\title{
V. DAS PARLAMENT VON METZ UND DIE EREIGNISSE NACH 1633
}

\section{Erste Ankündigungen, erster Widerstand}

Pläne zur Errichtung eines Parlaments als Berufungsgericht für die gesamten Trois-Évêchés gab es, wie dargestellt, bereits seit der Regierungszeit Heinrichs IV. Immer wieder waren seitdem auch entsprechende Denkschriften vor Ort entstanden ${ }^{1}$. Die endgültige Umsetzung ließ aber bis zum Jahresbeginn 1632 auf sich warten, als Ludwig XIII. in Metz erklärte, er beabsichtige nun die Errichtung eines Parlaments.

Der Zeitpunkt war gut gewählt: Der Besuch des Königs in den TroisÉvêchés neigte sich dem Ende zu und die unmittelbar auf die Verkündung der Parlamentserrichtung folgende Abreise machte es den Gegnern einer solchen Institution unmöglich, ihm ihren Protest persönlich vorzutragen. Dennoch reagierte man in Metz, wo das Gericht seinen Sitz haben sollte, sehr schnell. Schon am 13. Februar 1632 versammelten sich einige Ständevertreter. Der Schöffenmeister hatte das Beschwerdeheft, das man an den König schicken wollte, schon vorbereitet, während die Bewohner in den einzelnen Pfarreien noch gar nicht zusammengetreten waren. Nach dem Bericht eines gewissen A. François an den président Michel Charpentier ließ sich der Schöffenmeister von den fünf bis sechs anderen Mitgliedern dieser vom Adel kontrollierten "Ständeversammlung « nur mit Mühe davon überzeugen, zumindest die Entscheidungen der Pfarreiversammlungen abzuwarten. Wenn dem eben genannten Bericht Glauben geschenkt werden kann, hatte der Schöffenmeister dazu auch gute Gründe, denn nach François' Bericht war ein Großteil der Bewohner gerne bereit, die Entscheidung des Königs zu akzeptieren ${ }^{2}$. Das Protokoll der Ständeversammlung spricht hingegen vom Wunsch d'estre maintenus et conservés en franchises et privileges ${ }^{3}$. Eine Abordnung der Stände verließ Metz am 10. März 1632, angeführt vom Schöffenmeister persönlich" ${ }^{4}$.

Doch in Paris war man bereits vorgewarnt: Wenige Tage nach der Ständeversammlung vom 13. Februar 1632 hatte Nicolas Conrard, Kronanwalt beim

I Aus Metz: AMAE, CP Lorr. 11, fol. 10-14, 16f; aus Verdun: CP Lorr. 9, fol. 342, 387396.

${ }^{2}$ AMAE, CP Lorr. 11, fol. 48.

${ }^{3}$ Zitiert nach ZELLER, Réunion, Bd. 2, S. 274.

${ }^{4}$ Ibid. 
président in Metz, dem Siegelbewahrer in Paris bereits von den Ereignissen berichtet. Nicolas Conrard, der schon zuvor als Befürworter eines Parlaments aufgetreten war, versicherte noch einmal, daß diese Institution dringend notwendig sei und daß lediglich die städtischen Amtsträger wirklich dagegen seien, weil sie sich in ihren persönlichen Interessen getroffen fühlten. Die Masse der Bürger sei von Schöffenmeister und Magistrat mit der Ankündigung groBer finanzieller Belastungen durch das Gericht aufgehetzt worden. Indem er die egoistischen Einzelinteressen der Magistrate gegen das Allgemeinwohl stellte, konnte Conrard die Argumente der Vertreter der Stadt »die ihre eigenen Interessen der Größe des Königs, dem Wohl der Gerechtigkeit und der Erleichterung der armen Bevölkerung vorziehen« schon von vorneherein entkräften ${ }^{5}$.

Neben der offiziellen Gesandtschaft meldeten sich im Frühjahr 1632 auch andere Gruppen innerhalb der Stadt Metz in Sachen Parlament zu Wort: Der Adel forderte generell eine stärkere Beteiligung an den städtischen Ämtern ${ }^{6}$, die Metzer Protestanten eine chambre mi-partie, eine gemischtkonfessionelle Kammer nach den Regelungen des Ediktes von Nantes am neu zu schaffenden Parlament ${ }^{7}$.

Die offiziellen remontrances der Stände von Metz wurden gedruckt. Der Überlieferung nach zu urteilen, war die Auflage des achtseitigen Oktavheftchens relativ hoch ${ }^{8}$. Die Argumentation ist geschickt und entspricht dem üblichen Muster: Zunächst wird betont, daß sich die Stadt gegenüber dem Kaiser seit Jahrhunderten stets die Souveränität und sämtliche Gerichtsrechte bewahrt habe, und daß die Könige von Frankreich lediglich die Rechtsnachfolge der Kaiser angetreten hätten. Anschließend wird minutiös aufgezählt, welche Könige zu welcher Gelegenheit das Versprechen abgegeben hätten, nichts an den Rechten (droits) und Privilegien (privilèges) der Stadt zu ändern.

Geschickt setzen die Stände der Stadt Metz die Verhältnisse in ihrer Stadt dann von den Trois Eveschez de Metz, Toul \& Verdun, also den bischöflichen Territorien und denen der Hochstifte $a b$, mit denen sie nichts gemein hätten: estans differend d'iceux és mesures, monnoye, ressort, statuts, usages \& cou-

${ }^{5}$ Sinngemäße Ubbertragung der Autorin: qui préferent leurs interests particuliers à la grandeur du Roy, au bien de la justice, et au repos du pauvre peuple, AMAE, CP Lorr. 11, fol. $28 f$.

${ }^{6}$ Nach den Antworten auf diese Remonstration erschlossen, ibid. fol. 24.

${ }^{7}$ BnF, N.a.fr. 22701, fol. 194-199. Zu den chambres mi-parties vgl. MOUSNIER, Institutions, Bd. 1, S. 304; MIECK, Entstehung, S. 241.

${ }^{8}$ Ohne Anspruch auf Vollständigkeit zu erheben, sei auf folgende Exemplare verwiesen: A.C. Metz FF 213-1 (zitiertes Expl.); AMAE, Lorr. 11, fol. 30-33; Institut, Godefroy 7, fol. 147-154; BnF, Dupuy 498, fol. 190-196; BnF, N.a.fr. 7096, fol. 402: ein weiteres Exemplar konnte Zeller in der Médiathèque Metz, Ms 893 nachweisen, der Band ist jedoch im 2. Weltkrieg verbrannt. 
stumes. Man könne sich, so wurde in der Schrift weiter argumentiert, durchaus vorstellen, daß die anderen Städte und Territorien einen Vorteil an der Errichtung eines solchen Parlaments finden könnten, da es ihnen die langen Wege und hohen Kosten einer Berufung vor dem Reichskammergericht erspare. Für Metz jedoch bringe ein solches Gericht den Verlust der eigenen Institutionen, hohe Kosten und d'autres juges que du pays. Hier wird der Widerwille gegen auswärtige Richter deutlich, die, so argumentiert die Ständeversammlung weiter, der Stadt vorgesetzt würden, als ob es in Metz nicht genug gebildete und geeignete Personen gäbe, um die Rechtsprechung auszuliben. Mißstände in der bestehenden städtischen Rechtsprechung wurden durchaus zugegeben, allerdings könne man diese, so heißt es, leicht durch eine Reform von innen heraus beheben'.

Noch bevor seine Abgesandten mit diesen remontrances nach Paris aufgebrochen waren, hatte der Magistrat von Metz eine bemerkenswerte Kampagne gestartet: Alle Personen, die sich möglicherweise zum Fürsprecher der Stadt eignen könnten, wurden mit der Bitte um Unterstiutzung beim Protest gegen die Parlamentspläne angeschrieben, der Gouverneur von Metz Herzog Jean-Louis d'Épernon ebenso wie sein Sohn Louis de Nogaret, Cardinal de la Valette, sowie Richelieu, der für Lothringen zuständige Staatssekretär Claude Bouthillier, und der Großsiegelbewahrer Charles de Laubespine, marquis de Chateauneuf ${ }^{10}$.

Der Metzer Gouverneur Épernon, ohnehin auf Richelieu nicht gut zu sprechen, sicherte der Stadt seine Unterstützung zu, und auch sein Sohn wandte sich gegen die Parlamentspläne ${ }^{11}$. Doch die Entscheidung war gefallen. Schon Ende April 1632 rief die Stadt ihre Gesandten zurück, und der ohnehin in Paris ansässige Agent der Stadt wurde mit der Weiterverfolgung der Angelegenheit beauftragt ${ }^{12}$.

Insbesondere der Metzer Schöffenmeister Jean Baptiste de Villers, Sieur de Saulny, blieb dem Parlament gegenüber feindlich gestimmt. Eine anonyme Denkschrift an den Siegelbewahrer belastete den Schöffenmeister in dieser Hinsicht schwer: Er führe mit einer Handvoll Magistraten und Einzelpersonen die rébellions gegen das Parlament an, während alle Stände es leidenschaftlich herbeiwünschten und zu Gott flehen würden, ihnen die Gnade zu erweisen, daß der König es einrichte. Saulny sei hoch verschuldet und habe keinen Rückhalt in der Bevölkerung. Die Denkschrift empfahl seine Absetzung, ge-

${ }^{9}$ Raisons... A.C. Metz FF 213-1.

${ }^{10} \mathrm{Vgl}$. BnF, N.a.fr. 22668, fol. 110f. und 112f. (La Valette), 119f. (Épernon), 124f. (Richelieu), 129f. (Chateauneuf), 132 (Bouthillier).

${ }^{11}$ ZELLER, Réunion, Bd. 2, S. 276. Zum Verhältnis Épernons und des Cardinals La Valette zu Richelieu vgl. MOUSNIER, L'homme rouge, S. 385 u. VIGNAL-SOULEYREAU, Richelieu et la Lorraine, S. 314.

${ }^{12}$ ZELLER, Réunion, Bd. 2, S. 276. 
gen die kein Widerstand zu vermuten sei ${ }^{13}$. In ihrer Argumentation ähnelt diese Denkschrift dem Schreiben des Kronanwalts Nicolas Conrard vom Februar, sie ist jedoch wesentlich schärfer formuliert. Auch wenn die Polemik überdeutlich ist, kann doch vermutet werden, daß in der Argumentation gegen den Schöffenmeister ein Körnchen Wahrheit steckte. Tatsächlich war es ja weniger die Bevölkerung als vielmehr der Magistrat, der von der neuen Institution etwas zu befürchten hatte. Daß Saulny darüber hinaus kein »Mann des Volkes«, sondern ein Interessenvertreter der Patrizierschicht war, betont auch eine weitere Denkschrift aus dieser Zeit, die sich ebenfalls gegen den Schöffenmeister wandte ${ }^{14}$. Im Juli 1632 wurde er tatsächlich abgesetzt. Seinen Platz nahm der als Anhänger des Gouverneurs Épernon bekannte Drucker und Buchhändler Abraham Fabert ein ${ }^{15}$. Kurz nach Faberts Amtsantritt wurde das auf den 15. Januar 1633 datierte Gründungsedikt des Parlaments zugestellt, verbunden mit der Ankündigung, Kommissare in die Städte zu schicken, die die Parlamentserrichtung vorbereiten sollten ${ }^{16}$.

Die von den Metzer Ständen in ihrer Remonstration geäußerte Vermutung im Hochstift Metz, in Toul oder in Verdun könne man quelque advantage in der Errichtung eines Parlaments finden ${ }^{17}$, bewahrheitete sich allerdings nicht. Nur in Toul blieb es weiterhin ruhig ${ }^{18}$, während in Verdun beim Bekanntwerden der Parlamentsgründung Anfang August 1633 eine Ständeversammlung zusammentrat ${ }^{19}$. Bereits im Frühjahr 1633 waren aus Verdun erste Vorbehalte gegen das Parlament geäußert worden. Ausgerechnet die Amtsträger des französischen Königs in Verdun, der lieutenant Jean Gillet, der procureur Jean Drouin und der Gerichtsschreiber Regault, sahen in den Parlamentsplänen die Gefahr, daß sich die Bevölkerung wieder dem Kaiser zuwenden könne, und wandten sich mit dieser Argumentation an den König. Tatsächlich war es wohl eher aus Furcht um ihre Ämter, die durch das Parlament quasi überflüssig wurden. Jean Gillet und seine Mitstreiter betonten, es sei wichtig, auch weiterhin eine königliche Interessenvertretung direkt vor Ort zu haben. Sie schilderten, daß sie sich im Dienst des Königs beinahe ruiniert und sogar Verfol-

${ }^{13}$ AMAE, CP Lorr. 11, fol. 16 (zweites Exempl. CP Lorr. 10, fol. 630).

${ }^{14}$ Ibid. fol. 26.

${ }^{15}$ ZELLER, Réunion, Bd. 2, S. 276 - zu Fabert vgl. Kapitel VI.1.

${ }^{16}$ EMMERY, Recueil, Bd. 1, S. 1-14.

${ }^{17}$ In den Raisons... A.C. Metz FF 213-1.

${ }^{18}$ Das »Livre des enquéreurs« berichtet zwar von der Errichtung eines Parlaments, läßt dies jedoch gänzlich unkommentiert; auch Jean du Pasquier berichtet lediglich von den Protesten gegen die Pläne, bailliages zu errichten.

${ }^{19}$ Der Inhalt dieses Briefs wird sich kaum unterschieden haben von denen an die Magistrate von Toul und Metz, die bei EMMERY, Recueil, Bd. 1, S. 14-16 abgedruckt sind. Zur Einberufung der Stände in Verdun vgl. A.C. Verdun BB 6 (2. und 3.8.1633). 
gungen ausgestanden hätten, und forderten nun Ämter am Parlament von Metz oder besser noch ein eigenes königliches Présidial-Gericht in Verdun ${ }^{20}$.

Ähnliche Stimmen waren zum gleichen Zeitpunkt aus Toul zu hören: Die dortigen Amtsträger des Königs, die sich als siege royal bezeichneten, waren offenbar ebenfalls besorgt über die Parlamentspläne. Allerdings wandte sich der Protest vordergründig gegen die Ansprüche des Parlaments von Paris, das als Berufungsinstanz für die Gerichte des Domkapitels fungierte und diese Kompetenzen offenbar auf das gesamte Hochstift Toul ausweiten wollte. Kurz vor der Errichtung des beschlossenen Parlaments sollte aber auch noch einmal deutlich gemacht werden, daß man am siège royal in Toul nicht nur eine wichtige Aufgabe für die Vertretung königlicher Interessen erfüllte, sondern auch weiterhin eine souveräne Gerichtsbarkeit beanspruchte ${ }^{21}$.

Ein ähnliches Bestreben ließ sich zu diesem Zeitpunkt auch im Umfeld des Bischofs von Metz beobachten. Dort standen die bischöflichen Amtsträger in Vic schon seit einem Jahr in einer heftigen Auseinandersetzung mit dem président von Metz, der den Baron von Créhange, einen Vasallen des Bischofs, vorgeladen und damit das bischöfliche Adelsgericht übergangen hatte ${ }^{22} . \mathrm{Ob}-$ wohl das geplante Parlament in diesem Konflikt nicht erwähnt wird, ist die Stoßrichtung deutlich: Bisher hatte man im Hochstift Metz jede Unterordnung unter königliche Gerichte wie eben den président abgelehnt. Dies nun noch einmal zu einem Zeitpunkt zu betonen, zu dem der président durch ein sehr viel stärkeres Parlament ersetzt werden sollte, diente auch dazu, erst gar keine Anspruiche des Parlaments auf Gerichtsbarkeit im Hochstift aufkommen zu lassen. Daß der Bischof trotz seiner Verwandtschaft mit dem König nicht zu Konzessionen bereit war, hatte er bereits mit seiner Antwort auf den königlichen Vorschlag von 1631/32 zur Aufgabe seiner Souveränitätsrechte deutlich gemacht ${ }^{23}$. Auch in der Sache des Barons von Créhange hatte er die Partei seiner Amtsträger ergriffen und mit deutlichen Worten von Bouthillier ein meilleur traictement gefordert ${ }^{24}$.

Als das Gründungsedikt für das Parlament im Sommer 1633 bekannt wurde, reagierte der Bischof von Metz mit einer langen Denkschrift. Zunächst beschrieb er seine Rechte, sein Territorium, dessen Verwaltungsorganisation und die Einnahmen daraus, und bat den König dann, si la volonté du Roy est d'establir absoluemment une cour de Parlement a Metz, folgende Dinge zu bedenken: Der Bischof, einst prince souverain, stehe unter der Kontrolle des Parlaments, ja könne von diesem sogar verhaftet und angeklagt werden; er

\footnotetext{
${ }^{20}$ Institut, Godefroy 271, fol. 31 (23.3.1633).

${ }^{21}$ Ibid. fol. 37f. (9.4.1633 an Seguier).

${ }^{22}$ AMAE, CP Lorr. 10, fol. 629 und 540.

${ }^{23}$ AMAE, CP Lorr. 9, fol. 378, 380 und 383.

${ }^{24}$ AMAE, CP Lorr. 10, fol. 526.
} 
verliere alles Ansehen unter seinen Vasallen und residiere in seinen Schlössern als prince sans pouvoir ohne jede adlige Gefolgschaft; er erleide weiterhin große finanzielle Verluste, nicht nur durch den Wegfall der Einnahmen beim Verkauf der Gerichtsämter, sondern auch durch die Tatsache, daß er säumige Schuldner nicht mehr vor die eigenen Gerichte ziehen könne. Nicht zuletzt habe er vor dem Papst feierlich gelobt, die bischöflichen Regalrechte zu bewahren ${ }^{25}$.

Keines dieser Protestschreiben konnte die Errichtung des Parlaments verhindern, aber zumindest der Bischof von Metz erreichte das Versprechen, daß sich eine Kommission mit Möglichkeiten der Entschädigung auseinandersetzen werde ${ }^{26}$. Diese Kommission bestand aus Claude de Bullion, späterer surintendant des finances, und dem bereits bekannten Cardin Le Bret. Auch Bullion waren die lothringischen Verhältnisse vertraut: Bereits im Dezember 1631 war er mit einer Untersuchung zu den Rechten des Königs und des Bischofs von Metz über Moyenvic beauftragt gewesen und hatte dabei offenbar das Vertrauen des Bischofs Henri de Bourbon gewinnen können ${ }^{27}$.

Die Kommission machte mehrere Vorschläge, die in einer späteren Denkschrift des Bischofs aufgelistet sind. So sollte die bischöfliche Gerichtsbarkeit in ihrer gewohnten Form weiterbestehen, die Ämter innerhalb des Hochstiftes sollten auch weiterhin allein vom Bischof vergeben werden. Die Richter am Bailliage-Gericht sollten bis zu einem Streitwert von 400 livres souverän, d.h. ohne Berufungsmöglichkeit urteilen, und auch im strafrechtlichen Bereich sollten außer bei Leibesstrafen und Geldstrafen über sechs livres weiterhin souveräne Urteile möglich sein. Auch weitere Regelungen, die dem Bischof vor allem weiterhin die direkte Durchsetzbarkeit seiner Herrschaftsrechte und Steuerforderungen garantieren sollten, wurden getroffen. Die dariber hinaus versprochene Entschädigung durch den König in Höhe von 150000 livres muß den Bischof ebenfalls zufriedengestellt haben. Allerdings war diese ganz im Sinne der bereits mit der Kommission von Le Bret verfolgten Politik zweckgebunden: Sie sollte dazu verwendet werden, verlehnte und verpfändete Teile des Hochstifts wieder zurück zu kaufen ${ }^{28}$.

Mit der Ausnahme des Hochstifts, dessen Gerichte ja zuvor lediglich eine Berufung an das Reichskammergericht zugelassen hatten, fungierte das Parlament vor allem als Nachfolgeinstitution des président. Nach dem Vorbild der ubrigen Parlamente in Frankreich sollte es für Berufungen in allen zivilund strafrechtlichen Sachen zuständig sein, wobei das Ausdehnungsgebiet

${ }^{25}$ Institut, Godefroy 7, fol. 155-160.

${ }^{26}$ Nach einer etwa 1635 entstandenen Denkschrift, die die Einhaltung der vorgeschlagenen Entschädigungen anmahnt: A.D. Moselle, B 24-22.

${ }^{27}$ ZELLER, Réunion, Bd. 2, S. 244 f.

${ }^{28}$ A.D. Moselle, B 24-22, fol. 3v und 4r. 
ausdrücklich nicht nur die direkt von den städtischen und bischöflichen Institutionen kontrollierten Gebiete umfaßte, sondern auch die Lehnsherrschaften der einzelnen Bischöfe.

Das Gericht des président in Metz wurde, wie bereits angesprochen, aufgelöst, der Amtsinhaber Charpentier war nun als einer der Gerichtspräsidenten am Parlament tätig. Die Gerichtsbarkeit bei Streitigkeiten zwischen Militär und Zivilpersonen, eine der wichtigsten Zuständigkeiten des président, wurde für Metz direkt dem Parlament zugeordnet. In Toul und Verdun hingegen wurden die sièges royaux, bisher die Stellvertreter des président vor Ort, mit der Entscheidung dieser Prozesse beauftragt - eine Zuordnung, die den Kompetenzverlust dieser Instanzen allerdings kaum kaschierte ${ }^{29}$.

Neben dem Ersten Präsidenten kündigte das Gründungsedikt sechs weitere Präsidenten (présidents), 54 Gerichtsräte (conseillers), einen Kronanwalt für Formalfragen (procureur général), zwei weitere Kronanwälte für Sachfragen (avocats généraux du roi), vier Stellvertreter der Kronanwälte, neun Schreiber und Sekretäre, acht Gerichtsdiener und weiteres Personal zur Finanzverwaltung des Gerichts an.

Die Ämter am Parlament von Metz sollten, wie für höhere Magistraturen üblich, verkauft werden. Es scheint, daß dieser Verkauf über einen Pariser Geschäftsmann namens Jean Passart abgewickelt wurde oder werden sollte. Im Archiv des Außenministerium ist ein Vertrag überliefert, in dem Jean Passart das Recht zum Verkauf der Ämter am Parlament gegen die einmalige Zahlung von 300000 livres und die Übernahme der jährlichen Einkünfte (gages) abgetreten wird ${ }^{30}$. Wie diese gages gegenfinanziert werden sollten, wird im Gründungsedikt nicht präzisiert.

Die Besetzung der Ämter gestaltete sich schwierig: Obwohl die Amtsträger eines Parlaments grundsätzlich ganz oder zumindest zur Hälfte aus dem Ausdehnungsgebiet des Gerichtes stammen sollten ${ }^{31}$, und auch die Kommission von Cardin Le Bret im Jahr 1624 die Stimmung bereits für ein Gericht mit einer solchen Zusammensetzung testen sollte ${ }^{32}$, ist nur bei vier Amtsträgern des neuen Parlaments eine Herkunft aus Metz, Toul oder Verdun wahrscheinlich. Doch auch diese vier verteilten sich nicht gleichmäßig: Drei von ihnen stammten direkt aus Metz, der vierte aus dem Pays Messin ${ }^{33}$. Verstärkt wurde dieses Ungleichgewicht durch die konfessionelle Problematik.

Die Protestanten von Metz hatten sich mit ihrem Wunsch nach einer chambre mi-partie durchgesetzt und sechs der geplanten 54 Richterämter waren den

\footnotetext{
${ }^{29}$ Gründungsedikt; EMMERY, Recueil, Bd. 1, S. 9.

${ }^{30}$ AMAE, CP Lorr. 9, fol. 363f.

${ }^{31} \mathrm{Vgl}$. EMMANUELLI, Etat et pouvoirs, S. 55.

${ }^{32}$ Auftrag an Le Bret; gedruckt bei PICQUeT-MARCHAL, Chambre de Réunion, S. 128.

${ }^{33} \mathrm{Vgl}$. Kapitel VI.2.
} 
Angehörigen ihrer Konfession vorbehalten. Während von den Metzer Katholiken lediglich Nicolas Maguin in ein Parlamentsamt aufstieg, schafften es gleich drei Protestanten aus der Stadt und dem Umland, Abraham LeDuchat, Hilaire Adée und Charles de Lalouette du Bac.

Es ist leicht vorstellbar, welche Widerstände eine derartige personelle $\mathrm{Zu}$ sammensetzung des Parlaments hervorrufen mußte, denn die Befürchtung der Stände der Stadt Metz, daß in Zukunft auswärtige Richter, d'autres juges que $d u$ pays, vor Ort amtierten, hatte sich bewahrheitet und war von diesen schon in ihrem ersten Beschwerdeheft gegen das Parlament als untragbar dargestellt worden ${ }^{34}$.

Der Mangel an einheimischem Personal scheint jedoch weniger auf dem Unwillen, dieses zu berufen, als vielmehr auf mangelndem Interesse oder fehlenden finanziellen Mitteln bei den Bewohnern der Trois-Évêchés beruht zu haben. Ein Brief von Claude Sublet des Noyers, einem Vertrauten Richelieus, an einen unbekannten Adressaten in Metz berichtet nicht nur vom großen Interesse an den Parlamentsämtern, die die Väter der allerbesten Pariser Familien für ihre Söhne reservieren wollten, sondern auch von der Tatsache, daß einige Plätze für Einheimische reserviert seien und daß diesen der Vorrang gegeben werde.

Doch gerade an solchen Plätzen scheint kein großes Interesse bestanden zu haben, denn des Noyers forderte in seinem Brief den Adressaten in Metz auf, ihm doch geeignete Einheimische zu nennen, wenn er welche wisse ${ }^{35}$. Das relativ geringe Interesse an Parlamentsämtern insbesondere in Toul und Verdun ist möglicherweise aus der gleichen Perspektive zu betrachten wie die ruhige Reaktion auf die Parlamentspläne in diesen Städten: Fast scheint es, als habe man die geplante Institution zunächst kaum als etwas anderes angesehen als ein neues Présidial-Gericht.

Das von Claude des Noyers angesprochene Phänomen, daß vor allem die Söhne der Pariser Verwaltungselite von ihren Vätern in Parlamentsämter eingekauft wurden, war offenbar in der Hauptstadt Stadtgespräch und bot Anlaß zu einigem Spott. So berichtet Gédéon Tallemant des Reaux in seinen "Historiettes « süffisant, zum Zeitpunkt der Parlamentserrichtung in Metz seien in Paris besonders viele Theaterbärte verkauft worden, da die Räte am neugeschaffenen Parlament noch zu jung seien, um sich selbst welche wachsen zu lassen (der Bart gehörte zur Amtstracht eines Parlamentsrichters) ${ }^{36}$.

\footnotetext{
${ }^{34}$ A.C. Metz FF 213, 1.

${ }^{35}$ Ibid. 2 (12).

${ }^{36}$ Gédéon Tallemant DES REAUX, Historiettes, Paris 1960, S. 617.
} 


\section{Die Eröffnungsfeierlichkeiten}

Durch lettres patentes vom 7. Juli 1633 wurden zunächst Kommissare zur Errichtung des Parlaments eingesetzt. Sie sollten das Gründungsedikt den einzelnen Institutionen vor Ort verkünden sowie die Eröffnung vorbereiten ${ }^{37}$. Dieses Vorgehen wurde damit erklärt, daß sich der König noch nicht entschieden habe, wen er mit Ämtern am Gericht betrauen wolle, er aber die Menschen der Region nicht länger warten lassen könne. Wahrscheinlicher war wohl, wenn man den Brief von Claude Sublet des Noyers in Betracht zieht, $\mathrm{da} ß$ noch immer nicht alle Ämter einen Interessenten gefunden hatten.

Die vorläufig eingesetzte Kommission wurde angeführt vom späteren premier président Antoine de Bretagne und den vier maîtres des requêtes Antoine Barrillon de Morangis, Jacques Lefebvre de Caumartin, Dreux Daubray und Jacques Diel Sieur de Mireaumesnil, die vorläufig die Funktionen von Präsidenten ausüben sollten; sowie den späteren Präsidenten (P) und Räten (C) Michel Charpentier (P), François Blondeau (P), Jean Pinon (P), Jerôme Cauchon de Treslon (P), Claude Vignier (P) René de Chanteclerc (P), Jean de Bullion (C), Michel Marescot (C), Nicolas Rigault (C), Guillaume Fremyn (C) und Mathurin Biet de Mallebranche (C), die vorläufig als conseillers fungieren sollten. Als vorläufige Kronanwälte wurden Léonard Remefort de la Grelière und Nicolas Fardoil ernannt. Sie sollten auch weiterhin dem Gericht in diesem Amt dienen.

Die Zusammensetzung dieses provisorischen Gerichts aus maittres des requêtes, Staatsräten und dem Personal anderer großer Gerichte war nicht untypisch. Die chevauchées genannten Inspektionsreisen gehörten, wie bereits im dritten Kapitel erläutert, zum üblichen Aufgabengebiet der maittres des requêtes, und auch die Sondergerichte der sogenannten grands jours entsprachen in ihrer Zusammensetzung weitgehend der oben dargestellten Kommission ${ }^{38}$. Die genau umschriebenen Kompetenzen solcher Kommissionen sind auch hier zu erkennen: Zunächst sollten sich die Kommissare umgehend nach Metz aufmachen, das Gründungsedikt überall verkünden und registrieren lassen, darüber hinaus jedoch auch die materiell-rechtlichen Grundlagen für die Rechtsprechung des Parlaments schaffen. Konkret sollten sie ein Prozeßrecht beschließen und wenn nötig - und von den Ständeversammlungen so gewünscht - die coutumes des Zuständigkeitsbereiches neu fassen. Neben diesen

${ }^{37}$ Diese lettre patente ist gedruckt bei EMMERY, Recueil, Bd. 1, S. 11-13 (Anm.).

${ }^{38} \mathrm{Vgl}$. MOUSNIER, Institutions, Bd. 2, S. 466-488. 
Aufgaben sollten sie aber auch schon Rechtsprechungsfunktionen wahrnehmen $^{39}$.

Um die Bevölkerung auf die Ankunft der Kommissare vorzubereiten, wurden, wie bereits angesprochen, an die Stände und Magistrate der Städte Metz, Toul und Verdun Briefe geschickt, die um einen wohlwollenden Empfang ba$t^{40}{ }^{40}$. In Metz wurde Nicolas Maguin der Jüngere, Sohn des mehrfachen Schöffenmeisters und Druckers mit der heiklen Aufgabe betraut, diesen Brief zu verkünden. Seine Berichte an den Staatssekretär Bouthillier und Richelieu zeugen von der feindseligen Stimmung in der Stadt ${ }^{41}$. Interessant ist hierbei der Vergleich mit den Stadtratsprotokollen der entsprechenden Tage. Denn während Nicolas Maguin von Unruhen schreibt und anklindigt, daß der Magistrat eine neuerliche Gesandtschaft an den Hof schicken wolle und sich weigere, dem Parlament Räumlichkeiten zur Verfügung zu stellen, notieren die städtischen Protokolle nur kurz den Empfang Maguins und den Beschluß, dem König den Gehorsam zu leisten, der ihm zustehe. Einige Tage später wurde sogar beschlossen, den Parlamentskommissaren Wein zukommen zu lassen ${ }^{42}$. Von einer Gesandtschaft nach Paris ist in den Stadtratsprotokollen erst einige Tage nach dem feierlichen Einzug des Gerichts in Metz die Rede, allerdings sollte diese nicht die Aufhebung des Gerichts, sondern lediglich die Bestätigung der Privilegien erbitten ${ }^{43}$. Auch über die Planung der Eröffnungsfeierlichkeiten in Metz ist in den Protokollen des Stadtrates nichts zu lesen, während der französische Armeekommandant Saint-Chamond in einem Brief berichtet, da $B$ die Planungen problematisch waren, und betont, er habe erst deutliche Worte sprechen müssen, um den Ablauf mit den städtischen Vertretern zu regeln ${ }^{44}$.

Von der Ankunft der Kommissare und den Eröffnungsfeierlichkeiten des Gerichts, die am 26. August 1633 stattfanden, sind neben einem offiziellen Bericht, der noch im gleichen Jahr bei Jean Antoine gedruckt wurde, auch zwei Briefe uberliefert: Zum einen von Nicolas Rigault (einem der Kommissare zur Parlamentserrichtung) und zum anderen von »Joly«, vermutlich von Paul Joly, dem Sohn des 1622 verstorbenen président Pierre Joly an Pierre Dupuy $^{45}$. In der Zusammenschau ermöglichen die Dokumente ein deutliches Bild von den Ereignissen.

${ }^{39}$ EMMERY, Recueil, Bd. 1, S. 11-13.

${ }^{40}$ Ibid. S. 13-15.

${ }^{41}$ 4.8.1633 an Bouthillier und 7.8.1633 an Richelieu, AMAE, CP Lorr. 13, fol. 276 und 282.

${ }^{42} \mathrm{Vgl}$. dazu ZELLER, Réunion, Bd. 2, S. $277 \mathrm{f}$.

${ }^{43}$ Ibid.

44 AMAE, CP Lorr. 13, fol. 309.

${ }^{43}$ "Relation de ce qui s'est passé à l'establissement \& premiere ouverture de la cour du Parlement de Metz«, Metz 1633. Gedruckt bei EMMERY, Recueil, Bd. 1, S. 16-23 (Anm.). Brief von Joly an Dupuy, o.D.: BnF, Dupuy 498, fol. 218-220 (Original) und BnF fr. 16873, 
Am 16. August 1633 traf der designierte Parlamentspräsident Antoine de Bretagne in Verdun ein, um auf die anderen Kommissare zu warten. Er wurde von einer Abordnung der Stände der Stadt Verdun begrüßt. Am folgenden Tag empfing er auch eine Gesandtschaft aus Metz, die ihm mitteilen ließ, das Parlament sei dort herzlich willkommen ${ }^{46}$. Nach dem Eintreffen einiger Kollegen zog man dann, begleitet von einer Kompanie Karabiniers, in Richtung Marsla-Tour, einem kleinen Ort östlich von Metz, wo die Kommissare auf die noch fehlenden Kollegen trafen und die Nacht verbrachten. Am nächsten Morgen (23. August) zogen die Kommissare in sieben Kutschen und eskortiert von etwa 400 Reitern in Metz ein ${ }^{47}$. Der König hatte angeordnet, daß der Empfang in Metz dem eines Gouverneurs entsprechen sollte, der zum ersten Mal in seiner Stadt eintrifft ${ }^{48}$. Die genaue Begrüßung war jedoch, wie oben bereits erwähnt, umstritten. Schließlich einigte man sich darauf, die neuen Würdenträger am Stadtrand mit einer Abordnung der Stände zu begrußen, die Kanonen der Stadt und der Zitadelle abzufeuern und die große Glocke der Kathedrale, die berühmte »Mutte $\ll$, zu läuten ${ }^{49}$. In Metz angekommen, begrüßte der Abt von Saint-Arnoul, André Valladier, die Kommissare mit einer kleinen Ansprache für jeden Einzelnen. Der streitbare André Valladier, der 1616 den Traktat »De la souveraineté du Roi sur la ville de Metz« veröffentlich hatte, war einer der engagiertesten Anhänger des Königs in $\mathrm{Metz}^{50}$.

In den folgenden Tagen empfingen die Kommissare Abordnungen des Rates der Dreizehn, des Domkapitels, der Garnison, aber auch den Suffraganbischof Martin Meurisse und den Stellvertreter des Gouverneurs, Montmart. Auch die Vertreter der reformierten Gemeinde und die Juden der Stadt schickten eine Delegation. Der wegen seiner theologischen Traktate berühmte protestantische Pastor Ferry ${ }^{51}$, der die Kommissare im Namen der örtlichen Gemeinde begrüBen sollte, wurde, wie Paul Joly berichtet, très bien receu, comme il est homme d'estime et de réputation $^{52}$. Zunächst hatte es jedoch laut diesem Bericht innerhalb der Kommission sehr unterschiedliche Ansichten dariber gegeben, ob

fol. 205-207 (Kopie); Brief von Rigault, vermutlich ebenfalls an Dupuy, o.D., BnF, Dupuy 498, fol. 216f. (Original) und BnF fr. 16973, fol. 209 (Kopie). Die offizielle relation entspricht in etwa dem Text, der sich im "Mercure Français «, Bd. 9 (1633), S. 122-143, findet. Möglichweise stammt dieser Text aus der Feder von Theophraste Renaudot, Herausgeber der "Gazette de France«, und einer von Richelieus ১Öffentlichkeitsarbeiternc. Joly spricht in seinem eben genannten Brief davon, daß Monsieur Renaudot der Öffentlichkeit einen ausführlichen Bericht der Ereignisse geliefert habe.

${ }^{46}$ Nach der Schilderung Jolys, BnF, Dupuy 498, fol. 218.

${ }^{47}$ MiCHEL, Histoire du Parlement, S. 26.

${ }^{48}$ lbid.

${ }^{49}$ ZELLER, Réunion, Bd. 2, S. 278.

${ }^{50}$ Vgl. Kapitel VIII. 1 und MICHEL, Biographie, S. 531.

${ }^{31} \mathrm{Zu}$ Paul Ferry vgl. CHÂTELLIER, Lothringen, S. $114 f$.

${ }^{52}$ Brief v. Joly an Dupuy, BnF, Dupuy 498, fol. 218-220, hier 219r. 
man eine solche Abordnung überhaupt empfangen solle und ob die Protestanten als eigener Stand zu begreifen seien. Doch schließlich habe man sich geeinigt, die Protestanten so leben zu lassen, wie es ihnen der König erlaubt habe ${ }^{53}$. Der Briefschreiber zog nach der Aufzählung der verschiedenen »Begrüßungskomitees« dann folgenden Schluß: "Vom allerhöchsten bis zum allergemeinsten, niemand versäumte es, ihm [dem Parlament] seine Aufwartung zu machen $\aleph^{54}$.

In den Tagen darauf bereitete man die Eröffnungsfeierlichkeiten vor, wobei es noch ein Problem gab: Zwischen dem Suffraganbischof Martin Meurisse und dem Domkapitel herrschte offene Feindseligkeit. Es stand zu befürchten, $\mathrm{da} B$ das Domkapitel einer Messe des Suffragans nicht beiwohnen würde ${ }^{55}$. Erst nach Verhandlungen des Kronanwaltes Rémefort de la Grelière mit dem Domkapitel konnte hier eine Einigung erzielt werden ${ }^{56}$.

Die Eröffnungsfeierlichkeiten begannen am 26. August frühmorgens: Nachdem sich die Kommissare im sogenannten Palais, dem Sitz des Metzer Schöffenmeisters und zukünftigen Parlamentsgebäude, versammelt hatten, brachen sie gemeinsam in festlicher Kleidung zum Gottesdienst in der Kathedrale auf. Keiner der Berichte versäumte es, die Bekleidung der neuen Amtsträger ausführlich zu schildern: Die prächtigen Amtsroben - Parlamentspräsident Bretagne im hermelingefütterten Mantel und mit dem Barett, die vier maîtres des requêtes mit Roben aus glänzendem schwarzem Satin und die übrigen Räte in scharlachroter Amtstracht ${ }^{57}$ - sollten nicht nur den Rang der einzelnen Träger, sondern auch die Macht des Parlaments allgemein symbolisieren. Die Berichte zeugen von dieser Wirkung: Das Volk habe sich leicht vom Glanz der langen Mäntel und roten Roben blenden lassen, berichtete Paul Joly zufrieden nach Paris $^{58}$.

Beim Einzug in die Kathedrale wurden die Parlamentsrichter vom Domkapitel feierlich begrüßt und der Älteste des Kapitels hielt eine kurze Ansprache. Nicolas Rigault würdigte die Ansprache in seinem Bericht als parolles bien

\footnotetext{
${ }^{53}$ [...] de les laisser vivre comme le Roy leur avoit permis. Brief $v$. Joly an Dupuy, ibid.

${ }^{54}$ Sinngemäße Ubertragung der Autorin: ...que depuis les plus grands jusques a plus abiects personne ne dispensa de lui rendre ses debvoirs. Brief $\mathrm{v}$. Joly an Dupuy, ibid.

${ }^{55}$ MICHEL, Histoire du Parlement, S. 27. Meurisse, der 1632 eine Geschichte der Bischøfe von Metz verfaßt hatte, beschuldigte das Domkapitel und den Magistrat, sie würden die Drucklegung seines Geschichtswerkes absichtlich verzögern. Vgl. AMAE, CP Lorr. 13, fol. 16. Sein Werk nahm eindeutig Partei für den Bischof, für Frankreich und gegen die Ansprüche des Domkapitels auf Mitsprache im Bistum und die des Magistrats auf Unabhängigkeit, es wurde 1634 dann doch noch bei Jean Antoine in Metz gedruckt: MEURISSE, Histoire des Evesques.

${ }^{56}$ MiCHEL, Histoire du Parlement, S. 27.

${ }^{57}$ Vgl. ibid. sowie Relation...bei EMMERY, Recueil, Bd. 1, S. 17.

${ }^{58} \mathrm{BnF}$, Dupuy 498, fol. 220v.
} 
pensées de respect et submission ${ }^{59}$. Tatsächlich waren die Worte des Domherren sorgfältig gewählt, denn er verpackte geschickt die Ansprüche des Kapitels auf Wahrung seiner Rechte in der Versicherung seines Gehorsams: Er sei sehr glücklich, daß er in der Kathedrale solch eine illustre Gesellschaft begrüBen dürfe, die der König zur Errichtung eines Parlaments geschickt habe und die kein anderes Ziel haben könne, als das öffentliche Wohl und die Bewahrung aller Stände in ihren Gütern, ihrer Ruhe und ihren Würden ${ }^{60}$. Auch die Antwort Bretagnes war geschickt: Die Richter wüßten, daß das Domkapitel diese Ehre nicht ihrer Person, sondern dem König erweise, der sie geschickt habe, und daß die Ehrerbietung nur eine Fortsetzung der Beweise von Eifer und Wohlwollen für die königliche Sache sei, die das Domkapitel von jeher an den Tag lege ${ }^{61}$. Mit dieser Antwort war das Kapitel in die Pflicht genommen. Wollte es nicht von seiner angeblichen "schon immer verfolgten « Linie der Königstreue abweichen, mußte es gehorchen. Zudem war auch noch einmal klar gestellt, daß ein Gegner des Parlaments auch immer ein Gegner des Königs sei.

Nach diesem Wortwechsel nahmen die Kommissare in der Kathedrale Platz. Der Sitzordnung wurde dabei in den Berichten ein ähnliches Gewicht beigemessen wie der Bekleidung der Richter. Nach der Messe verließen der designierte erste Parlamentspräsident Bretagne, sein Stellvertreter Barillon und Suffraganbischof Meurisse gemeinsam und nebeneinander die Kirche - auch hier war es keineswegs gleichgültig, daß der Bischof quasi Seite an Seite mit den Parlamentsrichtern in das Palais schritt ${ }^{62}$.

Im neuen Sitzungssaal im Schöffenpalais eingetroffen, versuchte sich der Suffraganbischof vor den Richtern sogar in Astrologie. Er habe aus den Sternen gelesen, daß der Moment der Eröffnungsfeier wohl gewählt sei: Gerade befinde sich die Sonne im Zeichen der Jungfrau und wende sich der Waage zu, was ein gutes Vorzeichen für die Integrität und Gerechtigkeit sei, die man von dem neuen Gericht erwarte ${ }^{63}$.

Nach diesem pastoralen Blick in die Sterne öffnete man die Türen des Palais zum Vorplatz der Kathedrale hin und ließ das Gründungsedikt vorlesen. Hierzu gibt es in den einzelnen Berichten sehr unterschiedliche Aussagen: Nach dem offiziellen Bericht hatte sich vor dem Palais ein regelrechter Volksauflauf gebildet. Neben dem Schöffenmeister, dem Magistrat, dem Domkapitel, den Äbten und dem Adel sei eine très grande affluence et concours des Peuples desdits Pays et lieux voisins festzustellen gewesen, die alle aufmerksam der

${ }^{59}$ Ibid. fol. 216 r.

${ }^{60}$ Der Text der Ansprache wird referiert in der Relation, EMMERY, Recueil, Bd. 1, S. 17.

${ }^{61}$ Ibid.

${ }^{62}$ Ibid. S. 18.

${ }^{63}$ Ibid. 
Verlesung des Gründungsediktes und der anschließenden Ansprache Bretagnes gelauscht hätten ${ }^{64}$.

Nicolas Rigault hingegen berichtete weder von einem großen Volksauflauf noch von der Beteiligung des Magistrates. Auch die Ansprache Antoine de Bretagnes, in der die Vorzüge der neuen Institution dem Volk in den leuchtendsten Farben geschildert wurden, konnte nach seinem Bericht die Bevölkerung wohl kaum überzeugen, denn sie war viel zu leise. Höchstens zwei oder drei Personen direkt neben Bretagne hätten sie verstehen können, klagte Rigault $^{65}$. Paul Joly berichtete über die Teilnehmer der offiziellen Verlesung ebenfalls abweichend von der offiziellen Verlautbarung. Er bemerkte, daß der Schöffenmeister bei den Feierlichkeiten fehlte, und daß nur wenige den Grund für sein Fehlen kannten ${ }^{66}$, ging aber nicht weiter darauf ein. Ansonsten äußerte er sich zufrieden über den Verlauf der Eröffnungsfeierlichkeiten: Alles sei mit soviel honneur et dignité abgelaufen, wie man sich nur hätte wünschen können. Joly glaubte in den espritz du peuple eine völlige Neigung zum Gehorsam gegenüber den Anordnungen des Königs zu erkennen. Rigault führte dies darauf zuruick, daß le peuple sich vom Parlament eine bessere Rechtsprechung und mehr Milde als von den Dreizehn erhoffe ${ }^{67}$. Nach einer weiteren Ansprache der Kronanwälte, die mit antiker Gelehrsamkeit garniert, die Registration des Gründungsedikts erbaten, wurde dieses in die Register des neuen Parlaments aufgenommen ${ }^{68}$. Das Gericht war offiziell eröffnet.

Doch die Schwierigkeiten waren hiermit noch nicht überwunden. Rigault berichtete bereits von ersten Irritationen zwischen Parlament und Gouverneur: Der designierte Erste Präsident Antoine de Bretagne hatte zwei Tage nach der feierlichen Eröffnung zu einem großen Fest geladen. Nun waren nicht nur die vornehmsten Vertreter des Klerus und des Adels erschienen, sondern auch der Schöffenmeister und einige der Dreizehn. Nachdem man sich vom Tisch erhoben hatte, traf der Schilderung Rigaults zufolge die Nachricht ein, der Gouverneur sei gerade in die Stadt gekommen. Und so war die Tischgesellschaft innerhalb kuirzester Zeit auf die Parlamentsrichter reduziert, während die anderen Gäste nach draußen eilten, um den Gouverneur zu empfangen. Die so deutlich verkleinerte Tischgesellschaft hingegen debattierte noch: Sollte man dem Gouverneur gar keine Aufwartung machen, sollte man den folgenden Tag abwarten, oder sollte man sogleich eine Abordnung schicken? Schließlich wurde beschlossen, auf der Stelle drei Räte zur Begrußung La Valettes zu

\footnotetext{
${ }^{64}$ Ibid.

${ }^{65} \mathrm{BnF}$, Dupuy 498, fol. $216 \mathrm{f}$.

${ }^{66}$ Le Maistre Echevin n'y assista point, peu de personnes en scavent bien certainement le subiect..., ibid. fol. 218-220.

${ }^{67}$ Ibid.

${ }^{68}$ Relation..., EMMERY, Recueil, Bd. 1, S. 23.
} 
schicken. Rigault berichtet, diese seien mit allen Ehren empfangen worden. Darüber hinaus begrüßten Antoine de Bretagne und einige weitere Gerichtsräte den Gouverneur auch noch einmal persönlich. Dieser hingegen habe Bretagne keinen Gegenbesuch abgestattet und sei schon in der gleichen Nacht wieder abgereist, bemerkte Rigault, dem sich der Verdacht aufzudrängen schien, La Valette sei nur in die Stadt gekommen, um zu sehen, wie die Haltung dieser neuen Institution und ihr Benehmen ihm gegenüber sei ${ }^{69}$.

Genau wie der Schöffenmeister war also auch der Gouverneur La Valette erst am Tage von Bretagnes Fest aufgetreten, und bei der offiziellen Eröffnungsfeier nicht erschienen. Sein Auftreten, das Rigault als Gehorsamkeitstest für die Kommissare gewertet hatte, ließ bereits nichts Gutes ahnen. Sein Einzug während Bretagnes Fest hatte den designierten Gerichtspräsidenten nicht nur in Windeseile seiner Tischgenossen beraubt und damit deutlich gemacht, wer in der Rangfolge der Metzer höher stand als er, sondern es zeigte auch, $\mathrm{da} ß \mathrm{La}$ Valette es war, der sich vom neuen Parlament in aller Form begrüßen lie $B$, und nicht umgekehrt.

Aber auch die Abwesenheit des Schöffenmeisters Fabert bei der offiziellen Eröffnungszeremonie zeigt bereits künftige Konfliktlinien auf: Er war offenbar nicht geneigt, die neuen Richter anläßlich dieser Zeremonie untertänigst zu begrüßen. Als gleichgestellter Tischgenosse hatte er sich hingegen gerne $\mathrm{zu}$ Antoine de Bretagnes Fest einladen lassen.

\section{Die ersten Maßnahmen des Parlaments}

\subsection{Personelle Entscheidungen}

Um die städtischen Gerichte in Metz besser kontrollieren zu können, war schon vor dem Eintreffen der Kommissare im Juli 1633 durch königliches Edikt ein Procureur du Roi en la Justice ordinaire des Maître-Échevin \& Treizes \& Maison de Ville de Metz eingesetzt worden. Der König legte das Amt in die Hände von Nicolas Conrard, der sich bereits als Kronanwalt beim Gericht des président bewährt hatte und durch die Auflösung des Présidial-Gerichtes quasi arbeitslos geworden war ${ }^{70}$. Durch diese Entscheidung war dessen Konfrontation mit dem Magistrat fast schon vorprogrammiert, denn zuvor gab es keinen königlichen Interessenvertreter an den Metzer Gerichten, sondern le-

${ }^{69}$ Je crois qu'il n'estoit venu qu'a dessein de voir la contenance de ceste nouvelle compagnie et comme elle se comporteroit envers lui. BnF, Dupuy 498, fol. 216v.

${ }^{70}$ EMMERY, Recueil, Bd. 1, S. 31-35. 
diglich einen städtischen procureur. Conrard traf auf so großen Widerstand, $\mathrm{da}$ er sich schließlich per Parlamentsbeschluß regelrecht in sein Amt einklagen mußte ${ }^{71}$. Doch nicht nur Conrard, auch die dreizehn Gerichtsboten des président hatten ihre Aufgabe mit dem Parlament verloren. Sie adressierten im August 1633 ein Gesuch an den König und wurden danach am Parlament übernommen ${ }^{72}$.

Nach und nach begann das Parlament nun auch seine eigene personelle Aufstockung voran zu treiben. Die Kommissare führten vor allem in den Monaten August und September zahlreiche, zur Aufnahme an einem Parlament erforderliche, informations de vie et moeurs durch und nahmen die neuen Kollegen in ihre Mitte auf ${ }^{73}$. Die informations waren Befragungen verschiedener, vom Kandidaten selbst bezeichneter Personen von Rang, die Rechtgläubigkeit, Lebenswandel, Alter und Eignung des Kandidaten bestätigen mußten ${ }^{74}$. Gerade das Lebensalter stellte hierbei, wie oben bereits angedeutet, ein Problem dar. Viele der designierten Parlamentsrichter benötigten einen dispens de l'age, da sie noch nicht das erforderliche Alter erreicht hatten. Die Befragten mußten in solchen Fällen versichern, ihrer Meinung nach weise der Kandidat die benötigte Reife auf. Diese Untersuchungen bilden eine wichtige Quelle zur Biographie, aber auch zur Offenlegung der Verwandtschafts- und Freundschaftsbeziehungen der einzelnen Richter. Denn die im Dokument stets aufgeführten Beziehungen zwischen den zu Lebenswandel und Rechtgläubigkeit befragten Personen und den zukünftigen Parlamentsrichtern zeigen deutlich die Bande zwischen den einzelnen Beamtenfamilien. An einigen Beispielen wird auf diese Frage in Kapitel VI noch einmal einzugehen sein.

Die Frage nach der Rechtgläubigkeit, der religion catholique, apostolique et romaine, war bei den Befragungen ebenfalls von besonderem Gewicht. $\mathrm{Zu}-$ sätzlich beschloß man, daß jedes Parlamentsmitglied bei seiner Aufnahme ein Glaubensbekenntnis ablegen sollte ${ }^{75}$. Die sechs protestantischen Gerichtsräte mußten dieses Glaubensbekenntnis zwar nicht leisten, aber auch ihre Gewährsmänner mußten bezeugen, daß die zukünftigen Richter regelmäßig die actes d'un homme de ladicte religion in der Gemeinde ausübten ${ }^{76}$.

Die neuen Richter trafen nach und nach in Metz ein. Während der Erzähler Tallemant des Reaux und mit ihm wahrscheinlich ein Teil der Pariser Gesellschaft ihren Spott über das neue Parlament und sein Personal ausgossen, fand sich in Metz jemand, der auf jeden einzelnen Richter ein kleines Loblied sang:

$"$ A.D. Moselle B 943, fol. 9 (23.12.1633).

${ }^{72}$ EMMERY, Recueil, Bd. 1, S. 36-38.

${ }^{73}$ Die informations de vie et mours der Jahre 1633-1636 finden sich in der Mehrzahl in den A.D. Moselle B 1047.

${ }^{74} \mathrm{Vgl}$. zur Bedeutung dieser Befragungen: MOUSNIER, Institutions, Bd. 1, S. 223.

${ }^{75}$ Arrêt des Parlement de Metz vom 31.8.1633; EMMERY, Recueil, Bd. 1, S. 43.

${ }^{76} \mathrm{Vgl}$. die information zu Charles Lalouette de Bac: A.D. Moselle B 1047, fol. 173r. 
Esprit Gobineau, Sieur de Montluisant. Gobineau, der zuvor vor allem durch seine eigenwillige Beschreibung der Figuren am Portal von Notre-Dame de Paris aufgefallen war, hatte sich offenbar in den dreißiger Jahren in Metz angesiedelt $^{77}$. Dort hatte er Abhandlungen zu den Wundern des Berges Karmel und ein Werk mit dem Titel: "L'Ordre sacré de la saincte prestrise « veröffent$\operatorname{licht}^{78}$. Gobineau publizierte nicht nur eine Eloge auf das Parlament im allgemeinen, "La Royalle Themis qui contient les effects de la iustice divine, humaine, et morale de l'establissement de la Cour de Parlement a Metz«, sondern auch Akrostichen auf die Namen der einzelnen Richter ${ }^{79}$. Diese Gedichte, die jedoch kaum brauchbare Informationen zu den Personen liefern, lobten stereotyp und garniert mit Beispielen aus der antiken Mythologie den Gerechtigkeitssinn, den scharfen Verstand, die Milde, die Ehrwürdigkeit und die Verdienste der einzelnen Richter.

Neben den im Gründungedikt genannten Ämtern wurde schon kurz nach Ernennung der Kommissare die Errichtung einer Kanzlei am Parlament angeordnet, die das Gerichtssiegel verwalten sollte ${ }^{80}$. Zusätzliche Gerichtsdiener wurden vom König noch vor Arbeitsbeginn des Parlaments besetzt ${ }^{81}$. Hinzu kamen die bereits genannten Boten des président, die nun am Parlament eingesetzt wurden und die Polizeitruppe unter Leitung des prévôt provincial, zuständig für die Delikte von Militärangehörigen und Nichtseßhaften sowie auf Landstraßen, die 1633 ebenfalls aufgestockt wurde ${ }^{82}$. Um den Adel vor Ort mit dem Parlament zu versöhnen, wurden per Edikt im Dezember 1633 zusätzlich zwei Ämter für conseillers-chevaliers d'honneur am Parlament geschaffen, die jedoch aufgrund des starken Widerstandes des Parlaments erst 1648 und 1654 besetzt werden konnten ${ }^{83}$. Wegen der großen Anzahl an Richtern wurde das Parlament in Semester aufgeteilt, d.h. eine Hälfte der Präsidenten und Räte war von Februar bis Juli, die zweite Hälfte von August bis Januar in Metz tätig.

Die Einkünfte der Bediensteten sollten zunächst aus den Zöllen, die bei Warenbewegungen nach oder aus Zentralfrankreich erhoben wurden, bezahlt werden ${ }^{84}$. Doch schon im September 1633 wurde per Edikt eine Salzsteuer in den Trois-Évêchés angeordnet, um die Entlohnung des Gerichtspersonals zu

\footnotetext{
${ }^{77}$ MICHEL, Biographie, S. 200.

${ }^{78}$ Vgl. RONSIN, Répertoire, S. 32-34.

79 Esprit GOBINEAU DE MONTLUISANT, La Royalle Thémis, qui contient les effects de la justice divine, humaine et morale de l'établissement de la Cour de Parlement de Metz; \& les Acrostiches sur les Noms de Nosseigneurs de ladite Cour, Metz 1634.

${ }^{80}$ EMMERY, Recueil, Bd. 1, S. 17-25.

${ }^{81}$ Edikt vom Februar 1633 u. Oktober 1633, ibid. S. 26.

${ }^{82}$ Edikt vom September u. Oktober 1633, ibid. S. $44-46$.

${ }^{83}$ Ibid. S. 65-69.

${ }^{84}$ Arrêt des conseil du roi vom 16.2.1633, ibid. S. 28-29.
} 
gewährleisten ${ }^{85}$. Zwar war auch zuvor der Salzhandel im Gebiet des Parlaments nicht frei, wie dies zahlreiche Studien behaupten, aber es existierte keine Salzsteuer, sondern lediglich eine Vereinbarung mit dem Herzogtum Lothringen, die diesem das Monopol für den Salzverkauf in fast der ganzen lothringischen Region zugestand. Die Stadt Metz etwa nahm eine bestimmte Menge zu einem festgesetzten Preis $a b^{86}$. Im Edikt zur Einführung der Steuer (gabelle) wird ausführlich begründet, daß die ursprünglich vorgesehenen Zölle zur Deckung des Armeeunterhaltes nötig seien, und der König sich deshalb zu dieser Steuer gezwungen sehe, um den Unterhalt des Parlaments sicherzustellen. Der Schöffenmeister von Metz erhob sogleich Protest und die Stände der Stadt schickten eine vierköpfige Gesandtschaft zu Hofe ${ }^{87}$. Auch das Parlament beschloß, das Edikt vorerst nicht zu registrieren, sondern zunächst einmal den König zu bitten, die Einkünfte des Personals auch weiterhin aus den Zolleinnahmen zu bestreiten ${ }^{88}$. Zunächst hatten jedoch weder das Parlament noch die Gesandten der Metzer Stände Erfolg.

Um doch noch eine günstige Regelung zu erreichen, taten sich die drei Städte, die sonst meist im Alleingang ihre Interessen durchzusetzen suchten, zusammen $^{89}$ : Gemeinsam mit den Gesandten aus Toul und Verdun wurden auf dem Verhandlungswege die Modalitäten der neuen Steuer für die Städte günstiger geregelt. Die Bewohner selbst sollten nun die Verwaltung der Salzspeicher kontrollieren ${ }^{90}$. Doch auch dieses Verfahren war problematisch, denn den städtischen Vertretern war nur wenig an der pünktlichen Einnahme der Steuer gelegen, während die Parlamentsrichter auf ihre Einkünfte (gages) warteten. So wurden die Gesandtschaften des Parlaments, die bei Hofe um die Durchsetzung einer pünktlichen und vollständigen Bezahlung nachsuchten, Dauergäste $^{91}$.

\subsection{Die Durchsetzung der Parlamentsgerichtsbarkeit gegenüber anderen Gerichten}

In seinem Brief über die Eröffnungsfeierlichkeiten des Parlaments berichtete Nicolas Rigault auch von einem bezeichnenden Ereignis bei der ersten Gerichtssitzung am 29. August. Da habe man am Parlament erfahren, daß der Schöffenmeister auch weiterhin Berufungen vom Gericht der Dreizehn entge-

${ }^{85}$ Ibid. S. 46-51.

${ }^{86} \mathrm{Vgl}$. hierzu ZELLER, Réunion, Bd. 2, S. 281 (Anm.).

${ }^{87}$ EMMERY, Recueil, Bd. 1, S. 50 (Anm.).

${ }^{88}$ Arrêt vom 26.10.1633, ibid. S. 49.

${ }^{89}$ A.C. Verdun BB $6(11.3 .1634)$.

${ }^{90} \mathrm{Vgl}$. ZELLER, Réunion, Bd. 2, S. $281 \mathrm{f}$.

${ }^{91}$ Ibid. S. 383-387. 
gennehme $^{92}$. Die Parlamentsrichter, die diese Gerichtsbarkeit durch das Gründungsedikt abgeschafft sahen, untersagten daraufhin dem Schöffenmeister die Rechtsprechung ${ }^{93}$. Dieser protestierte umgehend und argumentierte, der König habe ausdrücklich die Privilegien der Stadt nicht beeinträchtigen wollen. Dabei verwies er auf den Wortlaut des Gründungsediktes. Tatsächlich war dort, abgesehen von der Stadt Mouzon, keine Rede von der Abschaffung einer Gerichtsbarkeit, sondern lediglich von dem Verbot von Urteilen in letzter Instanz und von einer Sonderregelung für die städtischen Gerichte, vor denen Urteile in letzter Instanz bei Fällen mit einem Streitwert von weniger als 100 livres weiterhin möglich sein sollten ${ }^{94}$. Rigault schrieb dazu, tatsächlich schien es ihm aus der Lektüre des Ediktes derjenige, der es aufgesetzt habe, die Absicht gehabt zu haben, jede Berufung mit einem Streitwert über einhundert Pfund von den Dreizehn vor das Parlament tragen zu lassen, weil es nützlicher für die Parteien sei, nur zwei Grade der Gerichtsbarkeit zu haben. Aber es sei auch wahr, daß dieser nicht beachtet habe, daß der Schöffenmeister nicht Vorsitzender des Gerichts der Dreizehn sei, sondern der eines anderen Gerichts, das über diesem stehe ${ }^{95}$.

Das Parlament schickte mit seinem Anliegen, das Gericht des Schöffenmeisters abzuschaffen, eine Abordnung zum König, der sich Ende August 1633 gerade im herzoglich-lothringischen Saint-Nicolas-de-Port aufhielt. Die Abordnung wurde freundlich empfangen, ebenso wie die der drei Stände von Metz, die etwa gleichzeitig mit der umgekehrten Bitte um Bewahrung der Gerichtsbarkeit des Schöffenmeisters in Saint-Nicolas eingetroffen war ${ }^{96}$. Doch eine Entscheidung wurde nicht getroffen. Zwar kehrte der Gesandte des Parlaments, der Kronanwalt Rémefort de la Grelière, mit der Versicherung Richelieus zurück, die Ansprüche des Schöffenmeisters hätten keinerlei Grundlage $^{97}$, doch eine offizielle Bestätigung dieser mündlichen Zusicherung sollte erst im Februar 1634 erfolgen $^{98}$.

Nach und nach begann das Parlament, das Gründungsedikt in den übrigen Orten des Zuständigkeitsgebietes bekannt zu machen. Bereits im August 1633,

\footnotetext{
${ }^{92} \mathrm{BnF}$, Dupuy 498, fol. $217 \mathrm{r}$.

${ }^{93} \mathrm{Vgl}$. das Sitzungsprotokoll des Parlaments in BnF, fr. 8690, fol. 8 r.

${ }^{94}$ Gründungsedikt, EMMERY, Recueil, Bd. 1, S. 1-16, hier 6-8.

${ }^{95}$ Ubertragung der Autorin. Et de vérité par la lecture de l'edict comme il y a apparence que celui qui l'a dressé a eu intention de faire que l'appel des sentences des treze au dessus de cent livres fust relevé au Parlement, estant plus utile au parties de n'avoir que deux degrés de jurisdiction, aussi est il vrai de dire qu'il n'a pas pris garde que le Maistre Echevin n'est pas le président des Treze, mais le chef d'un autre Conseil supérieur a celui des Treze.... BnF, Dupuy 498, fol. 217r.

${ }^{96}$ MICHEL, Histoire, S. 39.

${ }^{97}$ EMMERY, Recueil, Bd. 1, S. 42 (Anm.).

${ }^{98}$ Vgl. MiCHEL, Histoire, S. 39. Auf die Regelungen vom Februar 1634 wird an anderer Stelle noch einmal eingegangen.
} 
gleich nach der Eröffnungsfeier, hatte man angeordnet, das Gründungsedikt an alle officiers des lieux et sièges de ce ressort zu verschicken und es dort verkünden zu lassen ${ }^{99}$. Doch nun wurde noch einmal persönliche Präsenz gezeigt. Hierzu wurde eine Kommission von einem oder zwei Richtern in den entsprechenden Ort geschickt. Sie versammelte das örtliche Gerichtspersonal und manchmal auch noch Teile der Bevölkerung, und ließ das Edikt vorlesen. Dann wurde gefordert, das Edikt in den Registern des jeweiligen Gerichts zu registrieren und damit anzuerkennen. Von den Ereignissen wurde ein Protokoll angefertigt ${ }^{100}$. Es scheint hierbei, daß man sich zunächst vor allem um die Durchsetzung der Parlamentsgerichtsbarkeit in Metz bemüht hat, dann in gröBere Städte wie Verdun ${ }^{101}$, Toul ${ }^{102}$ und Vic-sur-Seille ging, und sich erst im Frühjahr 1634 die kleineren Orte wie Baccarat vorzunehmen begann.

Die Protokolle dieser Zeremonie aus Verdun zeigen ähnliche Konfliktlinien auf wie zuvor der Streit zwischen Parlament und Magistrat in Metz. Sie sollen hier wegen ihres aufschlußreichen Inhalts etwas ausführlicher besprochen werden, zumal sich ähnliche Ereignisse zumindest in Vic-sur-Seille und Toul vermuten lassen ${ }^{103}$.

Als die Parlamentsräte Michel Marescot und Nicolas Foucquet Ende Oktober 1633 in Verdun eintrafen, ließen sie zunächst vor den Vertretern der städtischen Gerichtsbarkeit und den Schöffen von Sainte-Croix das Gründungsedikt verlesen. Dann untersagten sie ihnen, weiterhin Berufungen vor das bischöfliche Berufungsgericht der salle épiscopale zu tragen. Berufungen sollten nun ab einem Streitwert von 100 livres und in allen Strafsachen direkt vor das Parlament kommen. Während die Schöffen von Sainte-Croix versicherten, sie seien prêts à obéyr, betonten die Richter der justice temporelle, sie seien im Namen des Bischofs, von dem sie ihre Ämter erhalten hätten, zum Protest verpflichtet.

${ }^{99}$ Gründungsedikt, EMMERY, Recueil, Bd. 1, S. $15 f$.

${ }^{100}$ Fünf dieser Protokolle konnten gefunden werden, die aus Verdun (städtische Gerichte, bischöfliche Gerichte sowie ein weiteres Protokoll zur Verkündigung vor dem Gericht des Domkapitels): A.D. Meuse 11 F 15, S. 1-12 und 11 F 49, fol. 151-154, sowie spätere aus Baccarat (Hochstift Metz, Juni 1634), La Garde u. Dieuze (Hochstift Metz, Juni 1634) und Villers-Bettnach (Herzogtum Lothringen, bailliage d'Allemagne, April 1634 - hier wurde, ebenso wie im Juni in Dieuze, versucht, den Einflußbereich des Parlament zu Ungunsten des Herzogs auszudehnen, was bereits auf die spätere Reunionspolitik hindeutet) A.D. Moselle B 504, fol. 7f. (Baccarat), 9f. (La Garde und Dieuze), 11 (Villers-Bettnach).

${ }^{101}$ Arrêt vom 27.10.1633, ausgeführt am 30.10.1633 durch Marescot und Foucquet, genannt im »Privileg« für Verdun vom 12.2.1634; EMMERY, Recueil, Bd. 1, S. 181.

${ }^{102}$ Arrêt vom 27.10.1633, ausgeführt am 2.11.1633 durch Fremyn und Joly, genannt im »Privileg« für Toul vom 12.2.1634; ibid. S. 171.

${ }^{103}$ Dies legt zumindest die Erwähnung von Remonstrationen nahe, die als Reaktion auf diese Verkündung offenbar in Vic und Toul entstanden. Für Toul, ibid. S.170f. Für Vic: AMAE, CP Lorr. 15, fol. 572-575. 
Noch schwieriger wurde es für Marescot und Foucquet vor den Vertretern des quasi entmachteten Gerichts salle épiscopale selbst. Trotz einer langen Ansprache, in der dargelegt wurde, $\mathrm{da} ß$ es durch verschiedene Regelungen des Königreiches verboten sei, mehrere Gerichtsinstanzen nebeneinander zu haben, und daß deshalb das Gericht seine Arbeit einstellen müsse, weigerten sich die Betroffenen, ihre Zustimmung zu geben, solange sich der Bischof wegen des Parlaments noch in Verhandlungen mit dem König befinde ${ }^{104}$.

Auch vor den Vertretern des bischöflichen Bailliage-Gerichts mußten Marescot und Foucquet mit guten juristischen Argumenten gewappnet sein, denn der Vorsitzende dieses Gerichts, der lieutenant de l'évêché de Verdun, argumentierte ausgesprochen geschickt: So warf er dem Parlament vor, es habe selbst das Bailliage-Gericht anerkannt, da es im September das Gründungsedikt zur Veröffentlichung an eben diese Institution geschickt habe. Ähnlich wie der Metzer Schöffenmeister verwies der lieutenant auf den Wortlaut des Gründungsedikts. Es stehe an keiner Stelle, daß das Bailliage-Gericht aufgelöst werden solle. Argumentationsmuster aus der Denkschrift des Bischofs von Metz lassen sich ebenso aufzeigen: Man könne nicht zulassen, betonte der lieutenant weiter, daß der Bischof von Verdun praktisch zu einem simple seigneur chastellain herabdegradiert und finanziell ruiniert werde ${ }^{105}$.

Auch der procureur des Bischofs argumentierte in diese Richtung. Er betonte, daß die zuvor angeführten Regelungen zur französischen Gerichtsbarkeit (nicht mehrere Gerichtsinstanzen) ohnehin nur für die simples hautes justices de France gedacht seien, und nicht für principautés régaliennes wie das Hochstift Verdun. Dies lasse sich dadurch beweisen, daß sogar der König selbst, als er den weltlichen Besitz des Bischofs während des Exils von Bischof François de Lorraine verwaltet hatte, die verschiedenen Instanzen beibehalten habe.

Ein regelrechtes Streitgespräch entspann sich zwischen dem eben genanten procureur des Bischofs und dem Vertreter des Kronanwaltes am siège royal in Verdun, der forderte, daß kleinere Berufungen vor das königliche Gericht (die vorherige Dependance des président) und größere direkt vor das Parlament zu gehen hätten. Schließlich übergaben die beiden Parlamentsräte Marescot und Foucquet den Vertretern des Bischofs ein Protokoll, in dem deren Protestreden niedergelegt waren und »mit denen sie Rechtsmittel einlegen könnten, wo sie es für gut hielten ${ }^{106}$. Bis dahin jedoch wurde ihnen ihre Amtsausübung bei mindestens 100 livres Geldstrafe verboten. Die Regelung erstreckte sich auch auf das Adelsgericht des Bischofs von Verdun ${ }^{107}$. Einige Tage danach wurde auch die Gerichtsbarkeit des Verduner Domkapitels unter Protest auf eine In-

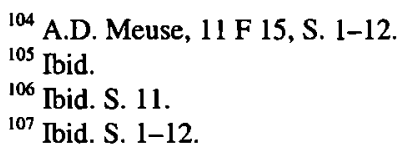


stanz gekürzt ${ }^{108}$. Doch der Widerstand der bischöflichen Amtsträger ging an anderer Stelle weiter: Sie begannen ein Gerichtsverfahren gegen ihre Entmachtung - ausgerechnet vor dem Parlament von Metz selbst ${ }^{109}$.

Auch im Hochstift Metz sollten nun die verschiedenen Instanzen, degrées de jurisdiction, innerhalb eines Territoriums abgeschafft werden. Mit einem arrêt vom 5. Januar 1634 ordnete das Parlament nicht nur an, daß das Gründungsedikt in einigen zwischen dem Hochstift und dem Herzogtum umstrittenen Orten verkündet werden solle, sondern untersagte auch dem Bischof von Metz den Unterhalt von zwei verschiedenen Gerichten an einem Ort. Dies betraf jedoch offenbar nicht die Rechtsprechung des Bailliage-Gerichts, dem ausdrücklich vorbehalten wurde, bis zur Summe von 1000 livres souverän, d.h. ohne Berufungsmöglichkeit, zu urteilen, sondern die lokale Gerichtsbarkeit im Hauptort Vic-sur-Seille. Dazu wurden die Richter des Metzer Bischofs noch einmal aufgefordert, in Strafsachen dafür zu sorgen, da $B$ in jedem Fall Berufung direkt beim Parlament eingelegt werde ${ }^{110}$.

Aus Verdun und Toul wurde offenbar nach den oben geschilderten Ereignissen, ebenso wie schon vorher aus der Stadt Metz, eine Beschwerdeschrift an den König geschickt. Über alle drei Schreiben sowie die Klage der bischöflichen Amtsträger von Verdun vor dem Parlament beriet der conseil du roi im Februar 1634 gemeinsam. Die Überschrift über dem dabei getroffenen Beschluß zu Verdun besagt, daß mit diesem Beschluß die Privilegien von Bischof und Domkapitel bestätigt würden ${ }^{111}$. Auch das am gleichen Tag für Toul erlassene arrêt bestätigt laut Überschrift die Privilegien von Bischof, Domkapitel, Magistrat und Bewohnern von Toul ${ }^{112}$.

Doch faktisch waren diese sogenannten Privilegien lediglich Bestätigungen des vom Parlament geschaffenen status quo. Zwar wurde für Toul von der Regelung Abstand genommen, es dürfte keine zwei Instanzen der Gerichtsbarkeit in einem Ort geben, doch blieb es bei der Tatsache, daß alle Gerichte ab einem Streitwert von 100 livres in Zivilsachen sowie in allen Strafsachen Berufungen vor dem Parlament von Metz zulassen mußten. Auch die vom Domkapitel in Toul gewünschte Beibehaltung der Berufung vor dem Parlament von Paris wurde nicht zugestanden ${ }^{113}$. Entsprechend schlecht wurde das Urteil in Toul aufgenommen: Der Schöffenmeister, die dix justiciers und der Magistrat der Stadt wandten sich sogleich gegen dessen Registrierung am Parlament ${ }^{114}$.

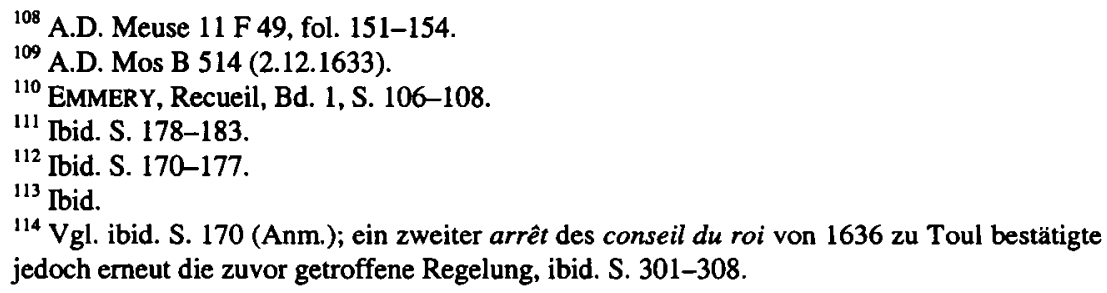


Auch die Entscheidung des conseil du roi für Bischof und Domkapitel von Verdun konnte wohl kaum für Zufriedenheit sorgen: Zwar wurde das von den Kommissaren abgeschaffte Gericht der salle épiscopale beibehalten, allerdings wurde es von einer Berufungsinstitution für alle städtischen und bischöflichen Gerichte zu einem Gericht der ersten Instanz herabgestuft. In den umliegenden Orten des Hochstifts blieb es bei der Zweiteilung der Instanzen. In erster Instanz waren die Ortsgerichte des Bischofs oder der Grundherren zuständig, in zweiter Instanz bei Zivilsachen das bischöfliche Bailliage-Gericht, in Strafsachen direkt das Parlament von Metz. Auch hiermit wurden die Kompetenzen des Gerichts der salle épiscopale beschnitten, denn zuvor waren Berufungen des Bailliage-Gerichts ebenfalls vor diese Instanz gegangen. Für die Gerichtsbarkeit in den Herrschaften des Domkapitels von Verdun änderte sich wenig, bis auf die Festschreibung des Appells vor dem Parlament, die auch hier noch einmal betont wurde ${ }^{115}$.

Die Antwort auf das Beschwerdeheft der Stände von Metz vom gleichen Tag war ebenfalls enttäuschend: Auch hier wurden das Gericht des Schöffenmeisters und der Dreizehn zu einer Instanz zusammengezogen. An der gabelle wurde ebenfalls festgehalten, es sei denn, wie es in der Antwort auf den entsprechenden Punkt der Remonstration hieß, man könne dem König eine Steuer präsentieren, die ein genauso hohes Aufkommen und weniger Belastungen mit sich bringe ${ }^{116}$.

Kurz zuvor hatte zudem der bereits 1633 ernannte Nicolas Conrard seine Arbeit als Kronanwalt an den städtischen Gerichten in Metz aufgenommen. Als er zum ersten Mal an einer Gerichtssitzung des Rates der Dreizehn teilnehmen wollte, wurde er vertröstet und sein Anliegen zunächst im Großen Rat der Stadt beraten. Zwar wurde Conrard im darüber erstellten Protokoll als Conrard, qui se dit pourveu de la charge de procureur du Roi en la chambre des Messieurs les Treizes bezeichnet, doch neben dieser verbalen Infragestellung seiner Position blieb die Reaktion im Rat schwach. Man hatte bereits in dem Beschwerdeheft gegen das Parlament die Bitte um Aufhebung des Kronanwaltsamtes eingeschlossen und beschlo $B$ nochmals in aller Form gegen diese Einrichtung zu protestieren und ein Protokoll über diesen Protest anzulegen, pour s'en servir en temps \& lieu ${ }^{117}$. Das Amt des Kronanwaltes bei den städtischen Gerichten in Metz blieb jedoch ungerührt von diesen ohnehin nur schwachen Protesten bestehen und die Wahrung der königlichen Interessen, auch im Bezug auf Berufungsfragen, schien somit gewährleistet.

${ }^{115}$ Ibid. S. $178-183$.

${ }^{116}$ Ibid. S. 158-170.

${ }^{117}$ Vgl. den Druck dieser Beratung, ibid. S. 35f. 


\section{Der Streit um das Parlamentsgebäude}

Schon in dem Brief, der dem Metzer Schöffenmeister und den Dreizehn die Ankunft der Kommissare zur Parlamentserrichtung ankündigte, hatte der König angeordnet, daß das neue Gericht bis zum Bau eines eigenen Parlamentsgebäudes im Schöffenpalais tagen sollte ${ }^{118}$. Die städtischen Magistrate mußten sich also in Zukunft ihr Amtsgebäude mit dem Parlament teilen. Immer wieder wurde die Frage nach dem Tagungsort des Parlaments daraufhin von städtischer Seite angesprochen, zumal, wie es in einer späteren Remonstration an den Gouverneur La Valette hieß, dem Magistrat nur noch ein einziger Raum in dem prächtigen Gebäude geblieben war ${ }^{119}$.

Auch die Umgebung des Schöffenpalais war zu einem Streitobjekt geworden: Die Verkaufsbuden im und an dem Gebäude waren durch ihre günstige Lage (am Gericht der Stadt, direkt gegenüber der Kathedrale) ohnehin sehr begehrt, und der Zustrom auswärtiger Rechtssuchender am Parlament versprach bald noch höhere Einkünfte. Der König hatte diese Buden bereits im Februar per Edikt drei Kaufleuten, Jean de Launay de Saint-Georges, Pierre Charbonneau de Fort-Écuyer und Bernard de Casenauve, zugesprochen ${ }^{120}$. Als dieses Edikt am Parlament von Metz registriert werden sollte, protestierten die Stände von Metz mit dem Argument, das Palais sei auf Kosten der Stadt errichtet worden und deshalb auch städtisches Eigentum. Daraufhin beschloß das Parlament, daß die drei Begünstigten zunächst einmal vor einer Kommission darlegen sollten, welche Örtlichkeiten sie denn genau beanspruchten.

Das Ergebnis der Befragung war für die Geschäftsleute der Stadt wohl kaum tragbar: Die drei vom König privilegierten Kaufmänner beanspruchten nicht nur die Läden im Erdgeschoß des Palais, sondern auch die gesamte Rue Vazelle, drei Häuser in der Grande Rue und alle unbebauten Plätze rund um das Palais ${ }^{121}$. Das Parlament erließ daraufhin folgendes Urteil: den Herren SaintGeorges, Fort-Écuyer und Casenauve wurden alle unbebauten Plätze am und rund um das Palais, als dem König gehörend und damit von ihm zu verschenken, zugestanden. Hier sollten sie so viele Läden, Häuser und Verkaufsstände errichten können »wie der Ort ertragen könne«, allerdings unter Einhaltung einiger Bauvorschriften. Über den Besitz der Häuser in der Rue Vazelle und der Grande Rue wurde vorläufig nicht entschieden ${ }^{122}$.

\footnotetext{
${ }^{118}$ Ibid. S. 14.

${ }^{119}$ BnF, N.a.fr. 22668, fol. 198.

${ }^{120}$ EMMERY, Recueil, Bd. 1, S. 27.

${ }^{121} \mathrm{Vgl}$. ibid. (Anm.).

${ }^{122}$ Vgl. ibid. S. 28 (Anm.).
} 
Die Fragen nach dem Tagungsort des Gerichts und den Verkaufsbuden wurden in einer Remonstration der Stände vom Beginn des Jahres 1634 erneut angesprochen, worauf der König in seiner Antwort aber nur darauf verwies, er könne nicht in ein laufendes Verfahren eingreifen ${ }^{123}$. Die endgültige Entscheidung durch das Parlament fiel im Juli 1634: Das Palais wurde als königlicher Besitz erklärt und die Läden den Herren Fort-Écuyer, Saint-Georges und Casenauve zugesprochen. Allerdings sollten bestehende Mietverträge noch weiterlaufen. Die noch immer unzufriedenen Stände wurden wieder an den König verwiesen ${ }^{124}$, so daß der Streit letztlich ungelöst blieb.

\section{Konflikte mit dem Militär}

Bereits zu Beginn des Jahres 1633 hatte sich angekündigt, daß die Beziehungen zwischen dem Parlament und dem Gouverneur von Metz nicht einfach werden würden. $\mathrm{Zu}$ diesem Zeitpunkt hatten sich sowohl der amtierende Gouverneur La Valette als auch sein einflußreicher Vater Épernon auf Bitten der Stände von Metz gegen das Parlament ausgesprochen und versucht, in dieser Richtung Einfluß zu nehmen ${ }^{125}$. Auch das bereits geschilderte Auftreten La Valettes während des Festes beim Gerichtspräsidenten Bretagne hatte bereits das Spannungspotential angedeutet ${ }^{126}$. Hinzu kam, daß dem Parlament durch die Abschaffung des Présidial-Gerichtes auch die Gerichtsbarkeit in Streitigkeiten zwischen Militärangehörigen und Privatleuten übertragen worden war ein Punkt, der schon zur Amtszeit des président stets für Reibereien mit der Militärverwaltung gesorgt hatte. La Valette war sich bewußt, daß er bei künftigen Kompetenzstreitigkeiten in diesem Bereich mit einem stärkeren Gegner rechnen mußte, als dies der président mit seinen wenigen Mitstreitern gewesen war. Zudem war die Aufsicht über die eigentliche Militärjustiz des prévôt des maréchaux nun durch die Anwesenheit eines Parlaments vor Ort wesentlich effektiver geworden.

Schon im September 1633 kam es zu ersten Spannungen, als das Parlament Ermittlungen gegen einen Angehörigen der Garnison aufnahm. Der Stellvertreter des abwesenden Gouverneurs protestierte erfolglos gegen dieses Vorgehen, das das Parlament mit einem Urteil vom 6. September rechtfertigte. Darin machte das Gericht seinen Anspruch auf umfassende Kompetenzen deutlich,

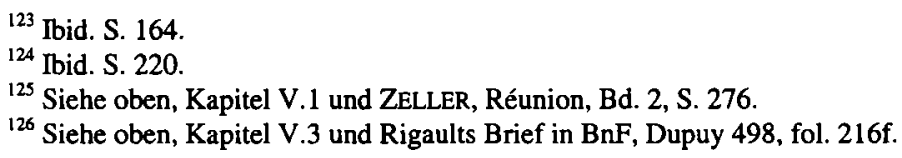


in dem es betonte, que la Cour étoit établie pour rendre la justice a chascun $^{127}$. Die Militärs waren beleidigt, und als der Gouverneur La Valette Anfang Oktober in der Stadt eintraf, reagierte er entsprechend kühl auf die Deputation des Parlaments, die ihm seine Aufwartung machen wollte. Er empfing die Parlamentsvertreter trotz entsprechender Ankündigung durch einen Gerichtsdiener nicht, sondern blieb im Bett und rührte sich nicht (ne bougea pas). Am Parlament, war man über dieses Vorgehen, das man extraordinaire fand, so empört, daß man beschloß, in Zukunft erst gar keine Delegationen mehr an den Gouverneur zu entsenden ${ }^{128}$.

Anfang November des Jahres 1633 kam es zu einem weiteren Zwischenfall. Obwohl der Anlaß eher geringfügig war, sollte sich daraus ein Streit entspinnen, der sich über Jahre hinzog. Die Gerichtsdiener des Parlaments hatten einem Offizier verboten, durch eine Passage direkt am Schöffenpalais, dem Parlamentssitz, zu reiten. Daraufhin wurden sie mit dem Schwert bedroht. Gleichzeitig beschuldigten Soldaten den Kutscher des Kronanwaltes am Parlament, einen Offizier im Vorbeifahren naßgespritzt zu haben und verprügelten diesen. Das Parlament ließ die Verantwortlichen verhaften und die Kronanwälte schickten einen wütenden Brief an den Kanzler: Der reitende Offizier habe nicht nur die Gerichtsdiener bedroht, sondern »Tausende von Beleidigungen « gegen das Gericht ausgesprochen ${ }^{129}$. Auch der Erste Präsident Antoine de Bretagne wandte sich noch einmal gesondert an den zuständigen Staatssekretär Bouthillier ${ }^{130}$. Gouverneur La Valette stellte diesem gleichzeitig seine Sicht der Dinge dar ${ }^{131}$. Nur mit Mühe gelang es Bouthillier, den Konflikt zu schlichten ${ }^{132}$.

Doch schon gab es eine erneute Provokation von Seiten der Garnison. Direkt gegenüber von Palais und Kathedrale hatte der Militärrichter (prévôt des maréchaux) einen Galgen errichten lassen, woriber sich einige Bürger beim Parlament beschwerten. Dieses erließ unverzüglich ein Urteil, das untersagte, Exekutionsinstrumente der Militärjustiz vor dem Palais zu errichten, ohne jedoch das Urteil durchsetzen zu können ${ }^{133}$.

In Paris hatten sich die Nachrichten vom schlechten Verhältnis zwischen Parlament und Militärgewalt bereits herumgesprochen: In der Parlamentssitzung vom 22. November 1633 berichtete der avocat général den erstaunten

\footnotetext{
${ }^{127}$ Registres secrets, A.D. Moselle, B 227, S. 40 (6.9.1633).

${ }^{128}$ MiCHEL, Histoire, S. 59, BnF, fr. 8690, fol. 8.

${ }^{129}$ Institut, Godefroy 271, fol. 87 (6.11.1633).

${ }^{130}$ AMAE, CP Lorr. 13, fol. 574 (7.11.1633).

${ }^{131}$ An Bouthillier: Ibid. fol. 579 (10.11.1633) und an den Kanzler: Institut, Godefroy 271, fol. 94 (17.11.1633).

${ }^{132}$ AMAE, CP Lorr. 13, fol. 608 (18.11.1633).

${ }^{133}$ MICHEL, Histoire, S. 61.
} 
Kollegen, daß in der Hauptstadt sogar das Geritcht umgehe, das Parlament werde von der Garnison belagert ${ }^{134}$.

Auch mit Gouverneur Bernard de La Valettes Nachfolger, seinem Bruder Cardinal Louis de La Valette, waren die Beziehungen kaum herzlicher, obwohl der Kardinal im Gegensatz zu seinem Bruder und Vater als Gefolgsmann Richelieus galt. Zwar tauschten beim Einzug des neuen Gouverneurs im Juli 1635 beide Seiten Höflichkeiten aus ${ }^{135}$, doch blieben die Kompetenzstreitigkeiten und die Frage, wer innerhalb der Stadt den Vorrang habe, weiterhin offen.

Dies wurde deutlich, als im Dezember 1635 ein Offizier im Hause eines Gerichtsrates einquartiert werden sollte. Es gehörte zu den Privilegien der Parlamentsrichter, von jeder Einquartierung befreit zu sein, so daß die Empörung am Parlament groß war. Der Gouverneur, der sich noch am Tag zuvor dafür eingesetzt hatte, einen Sohn des Parlamentspräsidenten Bretagne zum Abt von Haute-Seille in Metz zu machen ${ }^{136}$, beklagte sich am 14. Dezember 1635 in Paris, daß es wirklich schwierig sei de vivre avecque des Messieurs und schlug vor, das Gericht an einen anderen Ort zu verlegen ${ }^{137}$.

\section{Der erste Versuch zur Errichtung königlicher bailliages}

Die Kontrolle der untergeordneten Gerichte durch das Parlament hatte sich wie dargestellt als schwierig erwiesen. Im August 1634 beschloß die Regierung in Paris deshalb, nur kurz nachdem im Februar desselben Jahres die Gerichts»privilegien « der Städte und Bischöfe bestätigt worden waren, deren Gerichte ganz auszuschalten und solche Personen in die Gerichtsämter zu setzen que nous reconnoitrons estre fidelles et affectionnées à notre service et au bien de notre Etat ${ }^{138}$. Am Parlament von Metz seien so viele Berufungen gegen Urteile eingetroffen, die contraires à l'ordre, pratique, \& à nos Ordonannces seien, daß der König handeln müsse. Immer wieder werde das Parlament zudem mit geringfügigen Klagen belastet, weil die Rechtssuchenden ihren alten Gerichten nicht trauten.

\footnotetext{
134 Ibid. S. 62.

${ }^{135}$ Ibid. S. 63.

${ }^{136}$ AMAE, CP Lorr. 27, fol. 263 (13.12.1635).

${ }^{137}$ Ibid. fol. 270 (14.12.1635).

${ }^{138}$ EMMERY, Recueil, Bd. 1, S. 229-241
} 
Mit dieser Begründung ordnete der König im Edikt vom August $1634^{139}$ eine vollkommene Neuorganisation der gesamten Gerichtsbarkeit in den TroisÉvêchés an: Fünf bailliages sollten im Zuständigkeitsbereich des Parlaments geschaffen werden, in Metz, Toul, Verdun, Vic und Mouzon, diese wiederum zum Teil unterteilt in prévôtes oder châtellenies, deren Personal allesamt von königlicher Seite eingesetzt werden sollte ${ }^{140}$. Auch die lokalen Schöffenkollegien, die mit dieser Regelung ihre gesamten Gerichtskompetenzen verloren hatten, sollten umorganisiert werden. Vier Amtsträger sollten von den plus notables jeden Ortes gewählt werden, immer auf zwei Jahre, wobei jedes Jahr zwei der Amtsträger durch Wahl ausgetauscht werden sollten. Diese Gremien sollten vor allem für Verwaltungsangelegenheiten sowie die allgemeine »Polizei« zuständig $\operatorname{sein}^{141}$.

Ähnlich wie bei der Parlamentserrichtung waren dem Edikt konkrete Berichte aus den Trois-Évêchés vorausgegangen, die eine Neuordnung und effektivere Kontrolle der lokalen Institutionen gefordert hatten. So hatte sich der französische Jakobinermönch Raymond de la Molière schon im April 1634 an den Staatssekretär Bouthillier gewandt und vorgeschlagen, Présidial-Gerichte zur lokalen Aufsicht über die bischöflichen Gerichte zu errichten. Das düstere Bild, das er von der Lage in seinem neuen Wohnort Toul zeichnete, hat sicherlich zur Entscheidung für eine Neuorganisation der gesamten Institutionen beigetragen $^{142}$.

Der Widerstand aus den Trois-Évêchés war zunächst allerdings viel zu groß, um an eine Registration am Parlament von Metz zu denken: Schon am 1. August 1634 trafen die Ständevertreter der drei Städte zusammen, um dem Großsiegelbewahrer mitzuteilen, daß man kein Edikt zur Errichtung von königlichen bailliages dulden werde, und betrauten einen Advokaten am conseil du roi mit der Vertretung ihres Anliegens bei Hofe ${ }^{143}$.

Die drei Städte und ihre Ständevertreter waren zunächst tatsächlich erfolgreich: Auch in Paris war das Interesse an der Weiterverfolgung des BailliageProjektes eher gering, da zunächst andere Vorhaben Priorität hatten: Die Kontrolle des nun ebenfalls französisch besetzten Herzogtums Lothringen schien zunächst drängender ${ }^{144}$.

${ }^{139}$ Ibid.

${ }^{140}$ Ibid. S. 229-236.

${ }^{141}$ Ibid. S. 237

${ }^{142}$ AMAE, CP Lorr. 14, fol. 392.

${ }^{143}$ A.D. Meuse, 11 F 15, fol. 37.

$144 \mathrm{Vgl}$. zur Situation in Lothringen und der französischen Politik gegenüber dem Herzogtum 1634 VIGNAL SOULEYREAU, Richelieu et la Lorraine, S. 201-259. 


\section{Das Parlament von Metz und der conseil souverain de Lorraine}

Bereits in den ersten Monaten nach der Gründung versuchte man am Parlament, die Kompetenzen auch auf die Orte auszudehnen, in denen die Frage der bischöflichen Lehnshoheit zwischen Frankreich und dem Herzogtum Lothringen umstritten war. Selbst Gebiete, die von den Bischöfen schon vor langer Zeit an das Herzogtum verschenkt oder verpfändet worden waren, sollten unter die Kontrolle des Parlaments gelangen. Der lothringische Herzog war durch dieses Vorgehen zutiefst verärgert. Insbesondere die Anordnung des Parlaments, in Zukunft Berufungen aus den Orten Épinal, Blamont und SaintNicolas-de-Port vor das Parlament zu tragen, löste um die Jahreswende 1633/34 diplomatische Verwicklungen aus. Herzog Charles IV rüstete auf und plante immer offensichtlicher ein Zusammengehen mit den kaiserlichen Truppen $^{145}$. Es galt, ihn zum Einlenken zu bewegen, und da war der Übereifer der Richter in Metz eher hinderlich. Der Staatssekretär Bouthillier schrieb einen ausführlichen Brief an den Parlamentspräsidenten Bretagne, der zuvor das Vorgehen seines Gerichts als Vertretung königlicher Interessen gerechtfertigt hatte ${ }^{146}$ : Der König habe, so Bouthillier, considerations particulières, die geheim seien, aber aufgrund derer das Parlament die angrenzenden Territorialherren nicht verärgern dürfe ${ }^{147}$.

Nach der Abdankung von Herzog Charles IV und der Flucht seines Nachfolgers Nicolas-François unternahm das Metzer Parlament dann einen erneuten Vorstoß. Es wollte im April 1634 auch in Villers-Bettnach (Herzogtum Lothringen, bailliage d'Allemagne) seine Gerichtshoheit durchsetzen, ebenso zwei Monate später in Dieuze (ebenfalls bailliage d'Allemagne ${ }^{148}$. Diese Versuche waren höchstwahrscheinlich keine Einzelfälle: Das Parlament hat im Frühsommer 1634 immer wieder versucht, seine Gerichtsbarkeit, aber auch seine Steuerforderungen für die Einkünfte der Richter, auf das französisch besetzte Herzogtum auszudehnen, doch konnte es dabei nur wenig Erfolge aufweisen $^{149}$.

Gleichzeitig hatte Charles IV, der bald wieder offen den Herzogstitel beanspruchte, mit einem im Exil eingerichteten conseil souverain immer wieder Ordonnanzen gegen das Parlament von Metz erlassen. Das Gericht, das zunächst in Vesoul, dann in Sierck, Vaudrevange, Longwy und Luxembourg tagte, blieb bis 1661 bestehen und stellte eine ständige Herausforderung für

${ }^{145}$ BABEL, Zwischen Habsburg, S. 186f.

${ }^{146}$ AMAE, CP Lorr. 14, fol. 89f. (Bretagne an Bouthillier, 19.1.1634).

${ }^{147}$ Ibid. fol. 151 (Bouthillier an Bretagne, 29.1.1634).

${ }^{148}$ A.D. Moselle B 504, fol. 9f. (Dieuze), fol. 11 (Villers-Bettnach).

${ }^{149}$ CaBourdin, Histoire, Bd. 3,1, S. 198. Vgl. auch BABEL, Zwischen Habsburg, S. 187. 
das Parlament und den König dar ${ }^{150}$. Die Zeit war also gekommen, auch in Nancy ein königstreues Gericht für das besetzte Herzogtum Lothringen zu errichten. Am Metzer Parlament beobachtete man diese Pläne mit gemischten Gefühlen, denn eine Ausweitung des eigenen Kompetenzbereiches, wie man es dort eigentlich gewünscht hatte, stand nicht zur Debatte. Hinzu kam, daß man Bretagne zugetragen hatte, für die conseillers am Parlament, das wegen der großen Zahl von Amtsinhabern in Semester geteilt war, seien keine Positionen vorgesehen ${ }^{151}$. Nach einer Beratung schickte das Parlament schon im Juli 1634 eine Abordnung nach Paris, die den Großsiegelbewahrer bitten sollte, das Personal des Parlaments für den conseil in Nancy zu berücksichtigen ${ }^{152}$. Auch Richelieu wurde in diesem Sinne angeschrieben ${ }^{153}$.

Tatsächlich wurde der conseil souverain in Nancy dann, wie der König in einer lettre vom 16. September 1634 verkündete, zum größten Teil mit Richtern des Parlaments von Metz besetzt ${ }^{154}$. Erster Präsident wurde Michel Charpentier, vorher Präsident am Parlament und davor président royal in Metz, ein erfahrener Mann. Ihm zur Seite gestellt wurden zwei Präsidenten, siebzehn Gerichtsräte und ein Kronanwalt ${ }^{155}$. Auch der französische Gouverneur für das Herzogtum Lothringen erhielt Sitz und Stimme im neuen Gericht ${ }^{156}$.

Schon bald nach der Gründung kam es zu ersten Differenzen zwischen den ehemaligen Kollegen in Nancy und Metz: Am Parlament von Metz beharrte man weiter darauf, alle ehemaligen Lehensherrschaften der Bischöfe als $\mathrm{Zu}$ ständigkeitsgebiet anzusehen, während man diese am conseil souverain in Nancy zum dortigen Gerichtsgebiet rechnete. Die Vogesenorte Épinal und Remiremont sind ein gutes Beispiel für das Zuständigkeitsgerangel der ersten Jahre. Hier wurde die Gerichtsbarkeit nicht nur vom conseil souverain in Nancy, sondern auch vom Parlament von Paris und vom Metzer Parlament beansprucht. Die Richter in Metz hatten dort das Gründungsedikt verkündet und waren von örtlichen Institutionen als Berufungsinstanz anerkannt worden. Doch nun hatte auch der conseil souverain seine Kommissare in die Vogesenorte geschickt und die Amtsträger einen Treueid auf das Gericht in Nancy schwören lassen. Um die Verwirrung komplett zu machen, entsandte daraufhin das Parlament von Paris ebenfalls einen Gerichtsrat nach Épinal, der verkündete, die richtige Berufungsinstanz für Épinal sei das Présidial-Gericht in

${ }^{150}$ CABourdin, Histoire, Bd. 3,1, S. 196.

${ }^{151} \mathrm{BnF}$, fr. 8690, fol. 10r (registres secrets vom 24.7.1634).

152 Ibid.

153 AMAE, CP Lorr. suppl. 7, fol. 314f. (27.7.1634).

${ }^{154}$ Institut, Godefroy 343, fol. 491-494 (16.9.1634).

${ }^{155}$ CABOURDIN, Histoire, Bd. 3,1, S. 198.

${ }^{156} \mathrm{BnF}$, Dupuy 432, fol. 69 (lettre vom 16.9.1634). 
Sens und dariber das Parlament von Paris ${ }^{157}$. Am Parlament von Metz lieB man ein Urteil drucken und veröffentlichen, das die Ansprüche der Gerichte in Nancy und Paris als unrechtmäßig zurückwies ${ }^{158}$. Der conseil souverain widerrief seinerseits dieses Urteil und drohte jedem Kläger, der sich aus Epinal oder Remiremont nach Metz wenden wollte, mit hohen Strafen ${ }^{159}$.

Die Verwirrung in den Vogesenorten war damit vollkommen. In beiden Entscheidungen, von Parlament von Metz wie conseil souverain, wurde bei $\mathrm{Zu}-$ widerhandeln mit Strafen gedroht, und auch das Parlament von Paris genoß hohes Ansehen. An wen sollte man sich also in Zukunft wenden? Schließlich entschied der conseil du roi, den die Parlamentsrichter in Metz angerufen hatten: Er sprach alle ehemaligen bischöflichen Lehnsherrschaften der TroisÉvêchés, namentlich Hombourg, Saint-Avold, Nomeny, Marsal, Créhange, Thiecourt, Épinal, Blamont, Sarrebourg, Conflans, Apremont, VillersBettnach, die Länder des Priorats von Lay, die des Kapitels von SaintGengoul, Varangeville, Hattonchâtel, Malatour, Stenay, Jametz, die Vororte Saint-Epvre und Saint-Mansuy in Toul sowie Remiremont dem Parlament von Metz $\mathrm{zu}^{160}$. Hierbei ging es eindeutig um die Beanspruchung der Rechtsnachfolge der Bischöfe von Metz, Toul und Verdun durch den König und damit das Metzer Parlament. Diese Gebiete dem conseil souverain zuzusprechen hätte bedeutet, bei einer eventuellen Rückkehr des Herzogs auf sie verzichten zu müssen. Die Entscheidung sollte damit wegweisend für die Jahrzehnte später verfolgte Politik der Reunionen unter König Ludwig XIV. $\operatorname{sein}^{161}$.

\section{Die Konflikte um die Verlegung des Parlaments nach Toul}

Seit Ende des Jahres 1635 begannen allmählich Pläne für eine Verlegung des Parlaments Gestalt anzunehmen. Man könne mit den dortigen Richtern nicht leben, hatte der Gouverneur von Metz, der Kardinal La Valette, im Dezember 1635 geklagt $^{162}$. Auch der Konflikt zwischen dem Parlament und einer Halbschwester des Gouverneurs, der Äbtissin von Sainte-Glossinde in Metz, Loui-

${ }^{157}$ Die Ereignisse sind geschildert in den lettres patentes sur arrêt vom 31.1.1635; EMMERY, Recueil, Bd. 1, S. 259-269. Sowie in den arrêts von conseil souverain und Parlament von Metz; Institut, Godefroy 343, fol. 105 und 110.

${ }^{158}$ Ibid. fol. 105.

${ }^{159}$ Ibid. fol. 110.

${ }^{160}$ Lettres patentes sur arrêt vom 31.1.1635; EMMERY, Recueil, Bd. 1, S. 259-269.

${ }^{161}$ Die Frage der Ursprünge des Reunionsgedankens wird in Kapitel VIII.1 noch einmal aufgegriffen.

${ }^{162}$ Vgl. oben Kapitel V.6, Brief La Valettes in AMAE, CP Lorr. 27, fol. 270 (14.12.1635). 
se de La Valette, hat möglicherweise zur Forcierung dieser Entscheidung beigetragen ${ }^{163}$. Schon zuvor hatte Richelieu offenbar vor allem aus Gründen einer besseren räumlichen Verteilung der beiden königlichen Gerichtshöfe ebenfalls die Verlegung des Parlaments in Erwägung gezogen und hierbei auch schon Toul als künftigen Sitzungsort genannt: In einem Brief an Abel Servien hatte er bereits im April 1635 geschrieben: J'estime la résolution de la translation du parlement de Metz à Toul et du conseil souverain à Saint-Mihel très bon$n e^{164}$.

Mit Lettres patentes vom 10. Mai 1636 wurde diese Verlegung des Parlaments nach Toul schließlich angeordnet. Die ablehnende Haltung des Gouverneurs von Metz gegenüber dem Gericht wurde nicht angesprochen, sondern man begründete die Entscheidung mit der Bequemlichkeit non seulement pour ceux qui y rendront la justice, mais aussi pour ceux qui la demanderont ${ }^{165}$. Tatsächlich lag Metz, insbesondere für die Menschen im Westen und Süden des Zuständigkeitsbereiches (wie in den Ardennen und den Vogesen) sehr ungünstig, während Toul im Herzen Lothringens für eine größere Zahl an Rechtssuchenden leicht erreichbar war. Auch die militärische Situation schien nahezulegen, nach dem offenen Kriegseintritt Frankreichs das Parlament ein wenig von der sich abzeichnenden Frontlinie im Osten zurückzuziehen.

Am Parlament nahm man die Anordnung jedoch ablehnend auf. Toul war nicht nur wesentlich kleiner, sondern auch schlechter befestigt. Zudem grassierte dort zu diesem Zeitpunkt die Pest. Trotz der gesetzten Frist von acht Tagen wurde zunächst beschlossen, erst einmal die derzeit abwesenden Räte nach Metz zu laden ${ }^{166}$. Man wollte Zeit gewinnen, eine Strategie, die offenbar auch von den einzelnen Richtern angewandt wurde, denn einen Monat später mußte deren Ladung nach Metz wiederholt werden ${ }^{167}$. Erst am 12. September wurde ein Entschluß gefaßt: Man wollte der Anordnung vorerst nicht Folge leisten, sondern zunächst einmal Gesandte zu Hofe schicken, um dem König persönlich die Remonstrationen des Gerichts zu überbringen. Dort erfuhr man, der König sei mit seinen Truppen in die Picardie aufgebrochen und die Gesandtschaft wurde vertagt ${ }^{168}$. Ein kurzer Brief unterrichtete den König von dem Wunsch, ihm das Anliegen des Parlaments persönlich vorzutragen, und entschuldigte die späte Reaktion mit der Unsicherheit der Straßen ${ }^{169}$. Der advocat général Rémefort de la Grelière beschrieb Seguier die Stimmung bei der

${ }^{163}$ MICHEL, Histoire, S. 67.

${ }^{164}$ Denis L. AVENEL (Hg.), Lettres, instructions diplomatiques et papiers d'État du Cardinal de Richelieu, 8 Bde. Paris 1853-1877, S. 730.

${ }^{165}$ EMMERY, Recueil, Bd. 1, S. 312-314, hier S. 313.

${ }^{166}$ Arrêt vom 21.6.1636, nach EMMERY, ibid. S. 335.

${ }^{167}$ Arrêt vom 31.7.1636, nach EMMERY, ibid.

${ }^{168}$ Ibid. (Anm.).

${ }^{169}$ Institut, Godefroy 271, fol. 136. 
Parlamentssitzung vom 12. September 1636. La Grelière, der in seiner Position am Parlament eigentlich als Interessenvertreter des Königs fungierte, hatte große Mühe, seine Loyalität zu wahren. Sein Interessenkonflikt ist in diesem Brief deutlich spürbar: Einerseits gab es für ihn keinen Zweifel, »daß die Beweggründe des Königs und seines Rates stets sehr gut seien«. Auch die Intentions [...] bonnes et légitimes des Gouverneurs konnte er nicht in Frage stellen. Andererseits wies er darauf hin, daß die Angelegenheit »großes Gerede zum Nachteil des Königs, zur Mißachtung seiner Justiz und dem öffentlichen Glauben « verursache ${ }^{170}$. Geschickt machte er den Siegelbewahrer darauf aufmerksam, daß mit der Verlegung des Parlaments vor allem den Gegnern des Gerichtes geholfen werde ${ }^{171}$.

Noch deutlicher wurden die Argumente gegen die Parlamentsverlegung in einer Denkschrift von Nicolas Rigault dargelegt. Rigault, Ältester des Parlaments und ein beruhmter Philologe, bot in der von ihm abgefaßten Supplik des Parlaments an den König auf zehn eng beschriebenen Seiten alles an rhetorischem Können auf, was die damalige Zeit zu bieten hatte. Er führte nicht nur die Idee fort, die eigentlichen Befürworter eines solchen Umzuges könnten nur die Feinde des Königs sein, sondern drohte auch gekonnt mit einem Umschwung der öffentlichen Meinung in Metz, die dem König mangelnde Beständigkeit unterstellen könne. Hierbei wandte er den Kunstgriff der indirekten Rede an, mit der er die Argumente nicht selbst vorbrachte, sondern den Bürgern von Metz in den Mund legte: "Wir sehen uns in Eurer Stadt Metz unter Menschen, die sehr erstaunt über diese plötzliche Änderung sind und die uns beschuldigen, es sei noch keine drei Jahre her daß wir ihnen Eure Errichtungsurkunde überbracht hätten [...] die sie mit Freude und Erleichterung aufgenommen hätten [...] und nun würde man ihnen all diese Ehren wieder entziehen. [...] Und welche Erleichterung, sagen sie, und welche Freiheit und Sicherheit haben wir, wenn wir zu diesen Zeiten und während eines so grausamen Krieges unsere Gerechtigkeit an einem Ort suchen müssen, der nicht befestigt ist ${ }^{172}$. Ebenfalls geschickt in angebliche Gedanken und Reden der Bevölkerung verpackt malte Rigault die Gefahr einer regelrechten Revolution an die Wand. "Es ist leicht zu erkennen, was ihnen auf der Zunge liegt: daß die Stunde gekommen ist, in der sie ihren alten Zustand der Republik wieder-

${ }^{170}$...faict grandement parler au préiudice du Roi, au mespris de sa Justice et de la foi publique, ibid. fol. $72 \mathrm{f}$.

${ }^{171}$ Ibid.

${ }^{172}$ Sinngemäße Übertragung der Autorin: Nous nous sommes vues en votre ville de Metz parmi des gens qui s'estonnent de ce changement si soudain et nous reprochent qu'il n'y a que trois ans que nous leur avons porté vos lettres... qu'ils ont reçue avec joie et allégresse ... et maintenant on les prive de tous ces honneurs ... Et quelle commodité, disent ils, mais quelle liberté ou sûreté avons-nous, s'il nous faut aller quérir la justice en ce temps et durant une guerre si cruelle dans une place que n'est point fortifiée..., ibid. 
errichten ${ }^{173}$. Viele Metzer seien noch immer anfällig für die tentations $d$ 'un Estat populaire und sähen sich »unter einem falschen Vorwand der Freiheit als getrennt vom Königreich « $a^{174}$. Mit der Schilderung der schwierigen Bedingungen, unter denen das Parlament in Toul in Zukunft die königliche Autorität verkörpern solle, entkräftete Nicolas Rigault auch geschickt die Argumente des Gouverneurs: Er betonte, er könne sich nicht vorstellen, daß der Kardinal La Valette eine königliche Institution dem Spott der Bevölkerung aussetzen wolle ${ }^{175}$.

Doch der Gouverneur drängte mehr denn je. Immer wieder schrieb er nach Paris an den Staatssekretär Bouthillier, klagte ihm von den "Schwierigkeiten «, die die Messieurs ihm machten und bat ungeduldig um eine königliche Anordnung, um den Umzug endlich in Gang zu bringen, während Bouthillier vergeblich an La Valettes patience appellierte ${ }^{176}$.

Der Gouverneur sollte noch viel Geduld brauchen: Der König hatte dem Parlament mit Brief vom September 1636 eine Frist bis Weihnachten desselben Jahres gesetzt ${ }^{177}$, und als sich der Termin näherte, ohne daß das Parlament erkennbare Vorbereitungen traf, erging am 16. Dezember 1636 per lettre de cachet erneut der Befehl zum Umzug nach Toul ${ }^{178}$. Diese Anordnung traf Ende Dezember in Metz ein. Als das Parlament am Sylvestermorgen des Jahres $1636 \mathrm{zu}$ seiner nächsten Sitzung zusammentreten wollte, fand man die Tür des Schöffenpalastes verschlossen. Die Richter ließen den concierge herbeirufen, der ihnen berichtete, der lieutenant Roquespine, Stellvertreter des Gouverneurs La Valette, habe ihm am frühen Morgen den Schlüssel abgenommen, das Palais abgeschlossen und verbarrikadiert. Den daraufhin zu Roquespine entsandten Gerichtsdienern antwortete er, er habe auf Anordnung des Gouverneurs gehandelt und werde die Schlüssel nur auf direkten Befehl des Königs wieder aus der Hand geben. Der Versuch der Parlamentsangehörigen, mit Hilfe von zwei Schlossern die Türen öffnen zu lassen, schlug ebenfalls fehl: Eine Wachmannschaft der Garnison untersagte ihnen, sich dem Palais auch nur zu nähern. Dem Parlament, das sich ins Wohnhaus des Ersten Präsidenten zurückgezogen hatte, blieb nichts weiter übrig, als ein Protokoll der Ereignisse

${ }^{173}$ Sinngemäße Utbertragung der Autorin: ...il est aisé de lire qu'ils ont sur le bord des lèvres: Que l'heure est venue qu'ils reprendront leur ancien estat de république..., ibid.

174 Sinngemäße Übertragung der Autorin: soubs un faux prétexte de liberté comme séparéz du Royaume, ibid.

175 Ibid.

${ }^{176}$ Von La Valette: AMAE, CP Lorr. 29, fol. 369 (7.8.1636), fol. 418 (26.8.1636), fol. 434 (31.8.1636) und fol. 448 (3.9.1636). Von La Valettes Stellvertreter Roquespine: ibid. fol. 457 (14.9.1636). Antwort an La Valette: ibid. fol. 461-464 (15.9.1636).

${ }^{177}$ BnF, fr. 6647, fol. 84 (13.9.1636).

${ }^{178}$ EMMERY, Recueil, Bd. 1, S. 316 (Anm.). 
zu erstellen ${ }^{179}$. Dazu erließ man ein Urteil, das nicht nur verkündete, das Parlament werde seine Gerichtssitzungen bis auf weiteres im Haus Bretagnes abhalten, sondern auch Ermittlungen gegen Roquespine einleiten ${ }^{180}$.

Auch die Sitzungen im Haus des premier président wurden bald vereitelt. Noch am gleichen Tag, als sich die Richter nach dem Mittagessen wieder in Bretagnes Haus versammeln wollten, fanden sie es abgesperrt vor. Zwanzig bewaffnete Soldaten machten Bretagne zu einem prisonnier dans sa maison. Wieder wurde ein Protokoll erstellt ${ }^{181}$, das zusammen mit einer ganzen Anzahl von Briefen an die obersten Würdenträger des Staates abgeschickt wurde: Der König $^{182}$, Richelieu ${ }^{183}$, Seguier ${ }^{184}$ und Bouthillier ${ }^{185}$ wurden angeschrieben und um Unterstützung gebeten. In allen Briefen wird hierbei betont, es sei nicht im Interesse des Königs, das Parlament zu schwächen oder in eine andere Stadt zu verlegen. Man arbeite an der Remonstration für den König, die die Beweggründe zum Bleiben aufs genaueste erkläre, allein seien die Wege momentan zu gefährlich, um eine Abordnung nach Paris zu entsenden. Bis dahin hielten es die Richter für ihre Pflicht, weiter in Metz Recht zu sprechen ${ }^{186}$.

Die Soldaten vor Bretagnes Haus wurden am 2. Januar 1637 abgezogen und das Parlament tagte nun wieder dort ${ }^{187}$. Roquespine allerdings hatte ein Plakat mit einer Ordonnanz drucken und in ganz Metz aufhängen lassen, die neben anderen Regelungen allen Anwälten untersagte, noch Prozesse vor das Parlament zu tragen ${ }^{188}$.

Unter diesen Umständen sah der Metzer Schöffenmeister offensichtlich die Gelegenheit gekommen, wieder seine alte Position zurückzuerlangen. Ebenfalls per Plakat, auf dem, wie die Parlamentsrichter bemerkten, weder das königliche Wappen noch ein De par le Roi gedruckt war, verkündete er, daß das Parlament nach Toul verlegt werde und sich die Rechtssuchenden ab nun wieder an ihn zu wenden hätten ${ }^{189}$. In einer Ständeversammlung, an der angeblich mehr als 250 Personen teilnahmen, hatte der Schöffenmeister den Brief mit dem Befehl zur Verlegung vorlesen lassen und noch einmal verkündet, man

179 AMAE, CP Lorr. 29, fol. 636-639 und BnF, Dupuy 498, fol. 244f., gedruckt bei EMMERY, Recueil, Bd. 1, S. 316f. (Anm.).

${ }^{180}$ Arrêt vom 31.12.1636, ibid. S. 317 f.

${ }^{181}$ Ibid. S. $319 f$.

182 AMAE, CP Lorr. 29, fol. 632f., gedruckt bei EMMERY, Recueil, Bd. 1, S. $318 f$.

${ }^{183}$ BnF, Dupuy, 498, fol. 149, gedruckt bei EMMERY, Recueil, Bd. 1, S. 319.

${ }^{184}$ Institut, Godefroy 272 , fol. 110.

${ }^{185}$ AMAE, CP Lorr. 29, fol. 634f.

${ }^{186}$ Der Wortlaut der genannten Briefe ist sehr ähnlich. Zitiert wurde hier nach dem Brief an Bouthilllier, ibid.

${ }^{187}$ EMMERY, Recueil, Bd. 1, S. 322f.

${ }^{188}$ Ibid. S. 320.

${ }^{189}$ Ibid. S. 322 (Anm.). 
müsse in Zukunft keinen Ladungen vor dem Parlament mehr nachkommen ${ }^{190}$. Gouverneur La Valettes Stellvertreter Roquespine war ebenfalls nicht untätig und hatte, um seine Ordonnanz durchzusetzen, alle Anwälte kurzerhand aus Metz schaffen lassen. An den Toren verwehrten die Soldaten diesen den Wiedereintritt in die Stadt ${ }^{191}$. Die Plakate wechselten sich nun in schneller Reihenfolge ab: Nach Roquespines Ordonnanz und dem Aushang des Schöffenmeisters fanden die Bewohner von Metz bald darauf wieder ein Plakat des Parlaments vor, das diese Ordonnanz annullierte und daraufhin erneut ein Plakat von Roquespine, das wiederum die Entscheidung des Parlaments für ungültig erklärte. Am 9. Januar 1637 schließlich war an allen Kreuzungen der Stadt wieder ein Plakat des Parlaments zu sehen, das sämtliche vorhergehende Plakate annullierte ${ }^{192}$. Ein Leidtragender dieses Plakatwettstreites war der Drucker Claude Felix: Er war von Roquespine unter Gewaltandrohung daran gehindert worden, ein arrêt des Parlaments zu drucken, wurde daraufhin vom Parlament verhört und mit punition exemplaire bedroht ${ }^{193}$.

Der Gouverneur La Valette wußte nicht mehr weiter: Messieurs du Parlement me donnent des peines incroyables, ils tesmoignent ouvertement qu'ils ne veullent point obéir aux ordres $d u$ Roi, et font mille choses, klagte er bei Bouthillier und bat erneut um einen königlichen Befehl zur Verlegung ${ }^{194}$. Doch auch die Parlamentsrichter wandten sich auf der Suche nach Fürsprechern an hochrangige Persönlichkeiten der Regierung. Der Kanzler Seguier erhielt im Februar eine Denkschrift, in der noch einmal eindringlich vor den Gefahren einer Parlamentsverlegung gewarnt wurde ${ }^{195}$.

Im April 1637 traf ein weiterer lettre de cachet in Metz ein, der dem Parlament ausdrücklich befahl, umgehend die Stadt zu verlassen. Um die Ernsthaftigkeit seines Befehls zu unterstreichen, hatte sich der König in einem weiteren Brief noch einmal an den Parlamentspräsidenten Bretagne persönlich gewandt. Auch die Parlamentsangehörigen, die sich zu diesem Zeitpunkt in Paris aufhielten, wurden offenbar persönlich angesprochen und rieten ihren Kollegen nun, nach Toul zu gehen ${ }^{196}$. Man beschloß, am 15. April aufzubrechen und den Protest von dort aus weiterzufuhren ${ }^{197}$.

Der Empfang in Toul war weitaus weniger glanzvoll als vier Jahre zuvor in Metz, aber freundlich: Die Stände der Stadt, Bischof und Gouverneur begrüß-

${ }^{190}$ Ibid. S. 323 (Anm.).

${ }^{191} \mathrm{Vgl}$. procès verbal vom 5.1.1637, ibid. (Anm.).

${ }^{192}$ BnF, Dupuy 498, fol. 251, EMMERY, Recueil, Bd. 1, S. 321 (Anm.).

${ }^{193}$ BnF, Dupuy 498, fol. 258.

${ }^{194}$ AMAE, CP Lorr. 30, fol. 4 (3.1.1637).

${ }^{195}$ BnF, Dupuy 498, fol. 260-262.

${ }^{196}$ EMMERY, Recueil, Bd. 1, S. 324f.

${ }^{197}$ Arreté vom 7.4.1637, ibid. S. 326 (Anm.). 
ten die Richter, und man ließ einige Kanonenschüsse abfeuern ${ }^{198}$. Einige Tage nach der Ankunft in Toul brach eine Kommission mit Bretagne und Charpentier nach Paris auf, um erneut gegen die Verlegung zu protestieren ${ }^{199}$.

Aufgrund der Entsendung einer Kommission nach Paris und dem generellen Widerwillen der Parlamentsräte, sich in Toul aufzuhalten, litt das Gericht während der ersten Sitzungsmonate in Toul an so großem Personalmangel, daß einem Bericht des Touler Chronisten Jean du Pasquier zufolge nicht genug Richter anwesend waren, um ein gültiges Urteil fällen zu können. Man behalf sich mehrere Monate lang mit den in Toul ansässigen Juristen, unter ihnen auch Pasquier selbst. Die Ehre, für einige Monate die Position eines Parlamentsrichters einzunehmen, wurde für den Chronisten jedoch dadurch getrübt, daß er für seine Tätigkeit keinerlei Bezahlung erhielt, und die tatsächlichen conseillers die Gerichtsgebühren unter sich aufteilten. Doch während Pasquier nach dieser Tätigkeit zumindest als Advokat am Parlament zugelassen wurde, gingen seine Touler Kollegen meist völlig leer aus. Lediglich die Amtsträger des ehemaligen Présidial-Gerichts vor Ort, Louis Gillot, Louis Machon und [Charles] Darbamont wurden zu Advokaten bestellt ${ }^{200}$.

Die Entsendung einer Kommission des Parlaments nach Paris war ohne Erfolg geblieben, obwohl Antoine de Bretagne und seine Kollegen sogar vorgeschlagen hatten, nach Verdun umzuziehen, falls eine Rückkehr nach Metz unmöglich sei. Verdun erschien zumindest ein wenig größer und besser befestigt als Toul. Dort war man jedoch gegen diese Pläne. Der Stadtrat von Verdun bat den Gouverneur ausdrücklich, sich beim König gegen die Verlegung des Parlaments an die Maas auszusprechen ${ }^{201}$. Das Parlament von Metz blieb damit vorerst le Parlement de Metz séant à Toul ${ }^{202}$.

Trotz des wohlwollenden Empfangs waren auch in Toul Bedenken gegen eine Etablierung des Parlaments in der Stadt laut geworden. Sie wurden vor allem mit der Angst begründet, die protestantischen Mitglieder des Parlaments könnten ihre Konfession nun auch im bisher rein katholischen Toul etablieren. Domkapitel und Magistrat der Stadt wandten sich deshalb an den conseil du roi und erbaten ein Verbot für alle Protestanten, sich in der Stadt niederzulassen, das ihnen auch gewährt wurde. Allerdings waren die Angestellten des Parlaments hiervon ausdrücklich ausgenommen ${ }^{203}$.

Der Umzug ins ungeliebte Toul wurde dem Parlament bereits im Sommer 1637 durch eine deutliche Kompetenzausweitung versüßt: Mit Anweisung

\footnotetext{
${ }^{198}$ Nach der offiziellen relation, gedruckt bei EMMERY, ibid. (Anm.).

${ }^{199}$ Ibid. S. 325 (Anm.).

200 Jean du PASQUIER, Mémoires, hg. v. DAuLnOY, PILLEMENT, S. 130f.

${ }^{201}$ Stadtratsprotokoll vom 10.6.1637, A.C. Verdun BB 7.

${ }^{202}$ Diese Formel wurde von nun an als Selbstbezeichnung in den Dokumenten des Parlaments verwendet.

${ }^{203}$ Arrêt des conseil du roi vom 12.1.1638, AMAE, CP Lorr. 30, fol. 301-303.
} 
vom 13. Juli 1637 wurde der conseil souverain in Nancy aufgelöst, sein Personal wieder mit dem Parlament vereinigt und damit das Zuständigkeitsgebiet des Parlaments auf das gesamte Lothringen ausgedehnt ${ }^{204}$.

Dennoch war man mit dem neuen Amtssitz auch weiterhin nicht zufrieden: Um das Jahr 1642 trieb das Bemühen der Parlamentsrichter, Toul wieder verlassen zu können, besonders seltsame Blüten. Am Parlament war man nun sogar bereit, das Zuständigkeitsgebiet der Trois-Évêchés ganz aufzugeben und schlug in Paris eine »Verlegung « des Gerichts nach Tours vor, wo ein Parlament angeblich dringender benötigt werde ${ }^{205}$. Mit aufwendigen Rechnungen wurde hierbei versucht nachzuweisen, daß eine solche Verlegung für den König vö̈lig kostenneutral sei. Nachdem dieser Vorschlag offenbar auf wenig Interesse gestoßen war, suchte man am Parlament offenbar völlig wahllos nach einer weiteren Möglichkeit, wieder in einer größeren Stadt zu tagen: In ebenso aufwendig begründeten und gerechneten Vorschlägen wurde nun um eine Verlegung nach Poitiers oder Lyon gebeten ${ }^{206}$.

\section{Ein neuartiges Amt: der Intendant von Metz}

Metz war nach der Verlegung des Parlaments nach Toul wieder ohne eine königliche Institution - den Gouverneur ausgenommen. Bereits in den Januartagen des Jahres 1637, als die Verlegung des Gerichts angeordnet worden war, hatte der Metzer Schöffenmeister, wie von Nicolas Rigault in seiner Denkschrift befürchtet, erneut die alleinige Gerichtsbarkeit in Metz eingefordert ${ }^{207}$. Die neue Freiheit vom Einfluß der Parlamentsrichter, vom Gouverneur so dringend herbeigewlinscht, bereitete diesem nun Probleme. Nach dem Wegzug des Parlaments war bei der Entscheidung von Gerichtsverfahren zwischen Militär- und Zivilpersonen ein Vakuum entstanden, das der Schöffenmeister auszufüllen drohte.

Aus der Umgebung des Gouverneurs wurde deshalb vorgeschlagen, zur Aburteilung dieser Verfahren einen intendant de justice in Metz einzusetzen ${ }^{208}$. Für dieses Amt war derselbe Nicolas Rigault vorgesehen, der sich als Gerichtsrat am Metzer Parlament und Kronanwalt am conseil souverain in Nancy wortgewaltig gegen die Parlamentsverlegung ausgesprochen hatte. Er wurde

${ }^{204}$ Lettres patentes vom 13.7.1637, EMMERY, Recueil, Bd. 1, S. 340-343.

${ }^{205}$ AMAE, CP Lorr. 32, fol. 443 f.

${ }^{206}$ Ibid. fol. 445f. Auch A.D. Moselle, B 504, fol. 18.

${ }^{207}$ EMMERY, Recueil, Bd. 1, S. 320.

${ }^{208}$ AMAE, CP Lorr. 30, fol. 296 (o.D.). 
im Mai 1637 als intendant de justice et police en la ville de Metz, Pays Messin \& Terres de l'Evêché eingesetz ${ }^{209}$. Das Amt des Intendanten war weder dem Titel noch dem Aufgabengebiet nach neu in Metz, doch während es zuvor nur temporär begrenzte Aufgaben umfaßte, war - und dies war neu - Rigaults Position von Beginn an als Dauerposition gedacht ${ }^{210}$. Zunächst schien das Parlament von Metz nichts gegen diesen ersten Repräsentanten einer neuen Institution einzuwenden zu haben, zumal sich Rigault als Angehöriger des Gerichts und noch während seiner Tätigkeit am conseil souverain in Nancy die Interessen des Parlaments stets zu eigen gemacht hatte ${ }^{211}$.

Die Forderungen der Parlamentsopposition während der Fronde sollten später zeigen, wie tief der Graben zwischen Parlamenten und Intendanten in Frankreich sein konnte ${ }^{212}$ und bald zeigten sich auch in Metz zwischen dem konzilianten Rigault, der bei seiner täglichen Arbeit erfolgreich jeden Konflikt mit Magistrat und Gouverneur vermeiden konnte, und dem Parlament die ersten Irritationen. Im September 1638 erließ das Gericht - angeblich aufgrund der täglichen Beschwerden von nicht genannten Metzer Bürgern - ein Urteil, das den Intendanten aufs Schärfste angriff: Er habe entgegen dem Wortlaut seiner Ernennungsurkunde immer mehr Verfahren an sich gezogen und arbeite sogar mit dem Rat der Dreizehn zusammen, so daß auf diese Art immer mehr Urteile nicht mehr vor den ordentlichen Gerichten sondern vor dem Intendanten und den städtischen Würdenträgern gefällt würden. Nach Darstellung des Parlaments wollten die Magistrate durch die Zusammenarbeit mit dem Intendanten ihren Urteilen wieder den Charakter von letztinstanzlichen Entscheidungen geben und ein nouveau parlement unter städtischer Kontrolle in Metz aufrichten. Damit würden nicht nur Berufungen von Metzer Rechtssuchenden an das Parlament fast gänzlich unterbunden, sondern auch die Verkündung von dessen Urteilen und Ordonnanzen in der Stadt fast unmöglich, so »als ob die Stadt Metz nicht zum Zuständigkeitsbereich des Parlaments gehöre ${ }^{213}$.

Der Intendant Rigault erließ daraufhin ein arrêt, das noch einmal betonte, wie weitgespannt seine Kompetenzen seien, und lie $\beta$ sein Ernennungsschreiben erneut veröffentlichen. Ohne sich zu dem Vorwurf zu äußern, er mache gemeinsame Sache mit dem Magistrat, entschuldigte er diejenigen, die sich die "gefährliche und teure Reise " nach Toul sparen wollten und erlaubte ihnen deshalb weiterhin de s'adresser \& s'aquiesquer a la jurisdiction de celuy au-

${ }^{209}$ Lettres patentes vom 21.5.1637, EMMERY, Recueil, Bd. 1, S. 337-340.

${ }^{210} \mathrm{Vgl}$. dazu ZELLER, Réunion, Bd. 1, S. 286-293, der diese Entwicklung ausführlich schildert. Siehe auch MOUSNIER, Institutions, Bd. 2, S. 484-497.

${ }^{211}$ Hier sei nur noch einmal auf seine Supplikation gegen den Umzug des Parlaments nach Toul verwiesen. BnF, Dupuy 498, fol. 235-240.

${ }^{212}$ MOUSNIER, Institutions, Bd. 2, S. 497.

213 ...comme si la ville de Metz n'estoit du ressort du Parlement..., BnF, Dupuy 562, fol. 214 220 (13.11.1638), gedruckt bei EMMERY, Recueil, Bd. 1, S. 368-372. 
quel Sa Majesté a commis l'Intendance de la justice, pour en user selon la nécessité des temps \& des lieux ${ }^{214}$. Gleichzeitig hatte sich Nicolas Rigault an den conseil du roi gewandt und das Parlament der Beleidigung beschuldigt. Am 15. Dezember 1638 wurde ein Urteil des conseil erlassen, das alle Streitigkeiten zwischen Intendant und Parlament an sich zog und beiden bei Strafe untersagte, sich weiterhin zu bekämpfen ${ }^{215}$. Der Konflikt mit dem Parlament war damit scheinbar beigelegt, doch der Intendant mußte mit weiteren Schwierigkeiten kämpfen. Trotz oder auch gerade wegen seines guten Einvernehmens mit Stadtrat und Gouverneur hatte es der Intendant nicht geschafft, seine Bezahlung durchzusetzen. Immer wieder klagte er bei seinem Freund Pierre Dupuy über seine schwierige materielle Situation, doch konnte er an dieser nur wenig ändern ${ }^{216}$. Im März 1640 verließ Rigault schließlich enttäuscht Metz.

Sein Nachfolger Anne Mangot de Villarceaux, der schon Anfang 1641 durch den ehemaligen Parlamentsrichter Nicolas Vignier ersetzt wurde, war nicht mehr nur Intendant in Metz, sondern für das gesamte Gebiet der TroisÉvêchés und des Herzogtums Lothringen zuständig. Von nun an sollte diese Region in einer Intendanz verbunden bleiben. Beide Amtsinhaber haben in Metz kaum Spuren ihrer Tätigkeit hinterlassen. Es ist wahrscheinlich, daß sie in Nancy residierten. Die Beziehungen zum Parlament blieben jedoch schwierig: So wurde das Parlament um die Jahreswende 1644/45 erneut in eine erbitterte Auseinandersetzung mit seinem ehemaligen Richter und amtierenden Intendanten Vignier verstrickt ${ }^{217}$.

\section{Die Ereignisse von $1633-1640$ in Toul und Verdun}

In Toul waren die Beziehungen der königlichen Amtsträger untereinander und zum Magistrat der Stadt bereits vor der Errichtung des Parlaments problematisch. Insbesondere der lieutenant du roi Louis Gillot hatte immer wieder für Unruhe und Beschwerden gesorgt ${ }^{218}$. Der Touler Bischof Nicolas François de Lorraine war zudem eher geneigt, herzoglich-lothringische als königliche Inte-

${ }^{214}$ BnF, Dupuy 562, fol. 221 (25.11.1638), gedruckt bei EMMERY, Recueil, Bd. 1, S. 368f. (Anm.).

${ }^{215}$ BnF, Dupuy 562, fol. 222 (15.12.1638).

${ }^{216} \mathrm{Vgl}$. hierzu ZELLER, Réunion, Bd. 2, S. 291.

${ }^{217} \mathrm{Zu}$ Villarceaux und Vignier und ihren Positionen vgl. ZELLER, Réunion, Bd. 2, S. 291293.

${ }^{218}$ Hier sei nur als Beispiel das Schreiben v. Didier Viry zu Louis Gillot und der Konflikt um den maire von Maizières, Cheresq, um den Jahreswechsel 1632/1633 genannt: BnF, fr. 16890 , fol. 430-437 und AMAE, CP Lorr. 10, fol. 19, 236, 509, 624 u.ö. 
ressen zu vertreten und hatte eine Gruppe von Amtsträgern um sich gesammelt, die in enger Verbindung zum Herzogshaus stand. Als er im Januar 1634 seinem Amt zugunsten seines Suffraganbischofs Charles Chretien de Gournay entsagte und die lothringische Herzogswürde annahm, waren die Dinge kaum einfacher geworden. Denn obwohl sich König und Domkapitel in der Wahl Gournays einig waren, kamen nun Probleme mit der Kurie in Rom hinzu, die das Recht der Bischofsernennung in Toul ebenfalls beanspruchte. Faktisch sollte der Bischofsstuhl von Toul bis 1655 wegen dieser Streitigkeiten vakant bleiben $^{219}$. Das Domkapitel übernahm die eigentliche Macht, und der Kanoniker Jean Midot wurde zur Schlüsselfigur in der Verwaltung der geistlichen Territorien von Toul ${ }^{220}$. Die Stimmung innerhalb der Stadt schien in hohem Maße von Feindseligkeit, Mißtrauen und Eifersucht geprägt gewesen zu sein. Im Zentrum dieser Auseinandersetzungen stand wieder einmal der lieutenant am königlichen Gericht, Louis Gillot. Schon seit Ende des Jahres 1633 hatte Gillot ein Gerichtsverfahren gegen den örtlichen Militärbefehlshaber Christophe de La Vallée angestrengt, der ihn nach einem verlorenen Verfahren vor seinem Gericht angeblich immer wieder beleidigte ${ }^{221}$. Als sich La Vallée in seiner Eigenschaft als Vertreter des Gouverneurs dann im April 1634 einer bewaffneten Versammlung der Stadtbewohner entgegensetzte, nahm Louis Gillot die Gelegenheit wahr und ließ ihn kurzerhand verhaften ${ }^{222}$. La Vallée, der nur durch das Eingreifen des sich zufällig in Toul aufhaltenden Armeeführers Vicomte d'Arpageon wieder befreit werden konnte, sah die Ehre der gesamten Armee angegriffen und trug seinen Fall dem prévôt provincial und dem Armeeintendanten als oberste Militärrichter vor ${ }^{223}$. Gleichzeitig jedoch wandte sich Gillot an das Parlament von Metz, womit er erneut einen Kompetenzstreit zwischen Militärjustiz und Parlament provozierte ${ }^{224}$.

Darüber hinaus hatte der streitbare lieutenant Louis Gillot kurz nach der Abdankung des Touler Bischofs Nicolas François eigenständig den Schöffenmeister ernannt und einigen bischöflichen Amtsträgern einen Treueid abgenommen, d.h. die Funktionen des Bischofs übernommen. Das Domkapitel, dem von alters her die Verwaltung eines vakanten Bistums, aber auch des weltlichen Besitzes zukam, beschwerte sich darüber beim conseil du roi in

${ }^{219}$ Zwar amtierten kurzzeitig einige Bischöfe, sie haben jedoch entweder nie päpstliche Bullen erhalten oder nie einen Fuß in ihr Bistum gesetzt. Vgl. zum Ganzen: PIMODAN, Réunion, S. 390-392.

${ }^{220}$ CABOURDIN, Histoire, Bd. 3,2, S. 55.

${ }^{221}$ A.D. Moselle, B 729 (21.10.1633).

${ }^{222}$ Vgl. diese Schilderung bei Gobelin: AMAE, CP Lorr. 14, fol. 464.

${ }^{223}$ Vgl. die Briefe La Vallées, des Marschalls La Force und des Armeeintendanten Gobelin in AMAE, CP Lorr. 14, fol. 443 (La Vallée), 433 (Caumont La Force) und 464 (Gobelin).

${ }^{224}$ Vgl. dazu Kapitel VII.2.3. 
Paris, der dieses auch in seinen Rechten bestätigte ${ }^{225}$. Die von Louis Gillot ernannten städtischen Würdenträger wurden vor den conseil du roi zitiert, der erneut betonte, bis zum Abschluß des Verfahrens sei die getroffene Regelung einzuhalten. Dies schien nicht nur den von Gillot ernannten städtischen Vertretern unerträglich, auch Gillot selbst und die anderen königlichen Amtsträger in Toul sahen sich durch die hiermit festgesetzte Verringerung ihrer Kompetenzen auf Verfahren zwischen Soldaten und Zivilpersonen übervorteilt: Am 17. September 1634 schlossen Louis Gillot und der procureur am königlichen Gericht, Charles Compagnot, mit dem Schöffenmeister, den dix justiciers und dem Magistrat der Stadt einen Vertrag. Hier wurde nicht nur im Namen der gesamten Bürgerschaft (toute la bourgeoisie) der Protest gegen die von den königlichen Gerichten getroffene Regelung formuliert, sondern auch beschlossen, daß das königliche und das städtische Gericht in Toul gewissermaßen zu einer Instanz fusionieren sollten ${ }^{226}$.

Während der Stadtrat nun den König offiziell bat, diesen Vertrag zu ratifizieren und die Ernennung von Gillot und Compagnot in den Stadtrat anzuerkennen, protestierte das Domkapitel vor dem conseil du roi und schritt seinerseits zu einer Neuwahl der städtischen Amtsträger. Das Verfahren für eine solche Wahl bestand darin, daß das Domkapitel aus einer Liste auswählte, die zuvor von den Bewohnern in den Pfarreien erstellt worden war. Nur erschien die Bevölkerung nicht zu den einberufenen Wahlversammlungen und die schließlich vom Domkapitel ernannten Amtsträger wurden vom königlichen Gericht unter Leitung Compagnots umgehend wieder ihres Amtes enthoben. Auch die Vertreter der Stadt ernannten gemeinsam mit Gillot und Compagnot kurz darauf »ihre« Magistrate, die jedoch kurze Zeit danach wieder vom Parlament in Metz ihres Amtes enthoben wurden. Die endgültige Entscheidung fiel schließlich in Paris am königlichen Rat und zwar zugunsten des Domkapitels: Mit Urteil vom 23. Januar 1636 wurde dem Domkapitel auch weiterhin zugestanden, bei Vakanz des Bischofstuhles die Amtsträger gemäß dem Edikt von $1634 \mathrm{zu}$ ernennen ${ }^{227}$.

In Verdun, dessen Bischof François de Lorraine-Chaligny nach seiner Rebellion von 1627 erst seit 1631 wieder in Gnaden in sein Bistum eingesetzt worden war, fand Frankreich auch nach der Errichtung des Parlaments von Metz zunächst keine zuverlässige Stütze. Der lothringische Herzog Charles IV war 1635 wieder in seinem Territorium aufgetaucht und konnte sich zunächst

${ }^{225}$ 1.7. und 14. 7.1634, EMMERY, Recueil, Bd. 1, S. 215 f. und 221.

${ }^{226} \mathrm{Vgl}$. zu diesem Vertrag die Zusammenfassung seines Inhaltes in EMMERY, Recueil, Bd. 1, S. 303.

${ }^{227}$ Dieses arrêt, in dessen Urteilstext eine sehr ausführliche Schilderung der vorangegangenen und oben geschilderten Ereignisse enthalten ist, findet sich bei EMMERY, Recueil, Bd. 1, S. 301-308. 
auch auf großen Rückhalt in der Bevölkerung stützen ${ }^{228}$. Der Verduner Bischof François de Lorraine-Chaligny, dem in seinem Hochstift durch das Parlament, die Reform der städtischen Gerichte und die Salzsteuer immer weniger Gestaltungsspielräume blieben, schloß sich im Oktober 1635 seinem alten Verbündeten Charles IV an ${ }^{229}$. Er begann mit Truppenaushebungen und ließ Manifeste veröffentlichen, die den König aufs schwerste beleidigen mußten. Schon bald aber unterlagen der lothringische Herzog Charles IV und François de Lorraine-Chaligny erneut den königlichen Truppen ${ }^{230}$. Der König nahm seinen Sieg zum Anlaß, erneut den weltlichen Besitz des Bischofs sowie die vier großen Abteien zu beschlagnahmen und beauftragte einen Verduner Schöffen, Claude Valtrin, mit deren Verwaltung ${ }^{231}$. Magistrat und Bewohner hatten sich öffentlich von ihrem Bischof distanziert und eigenhändig zu den Waffen gegriffen, um die bischöfliche Belagerung der Stadt aufzuheben. Die Ausschaltung des Bischofs machte es nun für die Vertreter des Königs leichter, Kontrolle über den Magistrat zu gewinnen. Dies geschah vor allem über direkte Nominierung als loyal bekannter Personen in den Stadtrat. Bereits 1633 war ein gewisser Récicourt als Angehöriger der Garnison auf diese Art in das Schöffenamt aufgestiegen. Drei Jahre später wurde der Kommandant Dampval vom König zum doyen der Stadt ernannt. Immer häufiger griffen nun König und Gouverneur in die Verteilung der städtischen Ämter ein. Vom Rat war kaum noch Widerstand zu erwarten ${ }^{232}$.

Anders war die Situation bei den bischöflichen Amtsträgern im Hochstift Verdun: Wie eine Denkschrift aus dem Jahr 1635 schildert, verbargen sie kaum ihre Sympathien für den lothringischen Herzog ${ }^{233}$. Obwohl von den Vertretern der Krone vor Ort mehrfach angemahnt, schien man in Paris nicht gewillt, die bischöflichen Amtsträger nach der Beschlagnahme des Hochstiftes abzusetzen, sondern versuchte, sie für die Sache des französischen Königs zu gewinnen ${ }^{234}$. Auch mit dem Domkapitel von Verdun gab es Differenzen, da dieses sich ebenso wie die von ihm abhängigen Gemeinden weigerte, zur Bezahlung des Parlaments von Metz beizutragen. Einer der Sprecher dieses Widerstandes, der Kanoniker du Grens, wurde schließlich sogar verhaftet ${ }^{235}$.

${ }^{228}$ Vgl. dazu BABEL, Zwischen Habsburg, S. 198.

${ }^{229}$ LE MOIGNE in: GIRARDOT (Hg.), Histoire de Verdun, S. 145.

${ }^{230} \mathrm{Vgl}$. AMAE, CP Lorr. 26, fol. 653f. (Truppenaushebung, o.D.), fol. 648 und 652 (zwei Manifeste, vom 29.10. und 26.11.1635). Zum Ausgang des Feldzuges Charles IV vgl. CABOURDIN, Histoire de la Lorraine, Bd. 3,1, S. 200.

${ }^{231}$ KIEFFER, Verdun, S. 28.

${ }^{232} \mathrm{Vgl}$. ibid. S. $28-32$

${ }^{233}$ AMAE, CP Lorr. 26, fol. 316 (o.D.)

${ }^{234}$ Ibid. fol. 543 (15.10.1635) und 545f. (15.10.1635); CP Lorr. 27, fol. 435 (o.D.); CP Lorr. 29 , fol. 29 (11.1.1636).

${ }^{235}$ AMAE, CP Lorr. 29, fol. 267 (10.6.1636). 


\section{Die Einführung der königlichen Bailliage-Gerichte}

Sechs Jahre lang war von dem Projekt königlich kontrollierter BailliageGerichte nichts zu hören gewesen, als im Dezember 1640 per königlicher déclaration das Edikt vom August 1634 zu deren Errichtung in Kraft gesetzt wurde $^{236}$. Diese déclaration nannte keine Gründe dafür, daß das Edikt erst jetzt umgesetzt werden sollte, erwähnte allerdings, daß man auch weiterhin die bereits 1634 vorgebrachten Klagen über désordres \& abus innerhalb der alten Gerichtsbarkeiten erhalten habe und deshalb handeln müsse. Das Edikt war an einigen Punkten modifiziert worden: Man hatte insgesamt die Anzahl der Amtsträger erhöht und vor allem der Stadt Metz Zugeständnisse gemacht. Statt der ursprünglich vorgesehenen vier Schöffen sollten die Metzer nun zehn Schöffen wählen dürfen, die zusammen mit dem Schöffenmeister über die gleichen Ehren und Rechte verfügen sollten wie die städtischen Magistrate von Paris ${ }^{237}$. Zur Errichtung der königlichen bailliages wurden Richter des Parlaments als Kommissare ernannt und in die einzelnen Orte entsendet ${ }^{238}$.

Diese Errichtung geschah nicht ohne Protest. In Metz hatte man bereits vor dem Bekanntwerden der déclaration auf entsprechende Geriuchte reagiert und Richelieu angeschrieben. ${ }^{239}$ Eine Gesandtschaft wurde nach Paris geschickt, und der Magistrat versicherte sich der Unterstützung des Metzer Gouverneurs Jean de Lambert, der ebenso wie sein Vorgänger Louis de La Valette einer weiteren königlichen Institution in Metz sehr reserviert gegenüberstand. Man erwog sogar, sich einfach vom geplanten Bailliage-Gericht freizukaufen, da dieses wahrscheinlich ohnehin eher une affaire de finances et non pas d'estat $\operatorname{sei}^{240}$.

Doch diese Pläne schlugen fehl, und man versuchte es mit offenem Widerstand. Den königlichen Kommissaren wurde kein freundlicher Empfang in Metz bereitet: Als sie am 17. März 1641 in der Stadt eintrafen, fanden sie eine Szene vor, die sie lebhaft an die Situation im Dezember 1636 erinnern mußte. Das Schöffenpalais war verschlossen und wurde von einer Militärgarde bewacht. Auf Nachfrage erklärten die Wachen, sie hätten vom Gouverneur den ausdrücklichen Befehl erhalten, die Kommissare nicht einzulassen ${ }^{241}$. Ähnlich

\footnotetext{
${ }^{236}$ Déclaration vom 12.12.1640, EMMERY, Recueil, Bd. 1, S. 420-429.

${ }^{237}$ Ibid. S. 427.

${ }^{238}$ Ibid. S. 421-445 (Anm.).

${ }^{239}$ Brief vom 5.1.1641 zitiert nach ZELLER, Bd. 2, S. 295, Anm. 1, dessen Vorlage aus der Metzer Stadtbibliothek im Krieg zerstört wurde.

${ }^{240}$ Ibid.

241 Vgl. den Brief von Lambert an Bouthillier, in dem er sich für dieses Verhalten entschuldigt: AMAE, CP Lorr. 32, fol. 143.
} 
wie 1636 das Haus des Ersten Präsidenten des Parlaments zum Tagungsort des Parlaments geworden war, wurde nun das Haus des Kommissars Jerôme Cauchon de Treslon erster Amtssitz des Bailliage-Gerichtes. Der Metzer Gouverneur gab gegen das Zugeständnis, selbst als bailli von Metz emannt zu werden, seinen Widerstand bald auf ${ }^{242}$. In der Stadt jedoch blieb die Stimmung feindselig: Der Metzer Chronist Jean Bauchez schilderte die Ernennung der Räte am Bailliage-Gericht als eine Art Ämterladen, in dem Positionen verkauft wurden, von denen kaum jemand schätzen konnte, wie teuer sie waren $^{243}$. Alle seien, so Bauchez weiter, »ziemlich erstaunt, solch einen erneuten Wechsel der Dinge gegen den Wortlaut des alten Rechts zu sehen, aus dem seither verschiedene Gerüchte, Streitereien und Diskussionen zwischen den Bürgern entstehen ${ }^{244}$.

In Paris griff man nun gegen diese Gerüchte und Streitereien härter durch als in den Jahren zuvor: Der Schöffenmeister sowie ein Mitglied des Rats der Dreizehn wurden vor den conseil du roi geladen, und der Gouverneur Lambert wurde dazu aufgefordert, den Gehorsam notfalls auch mit Militärgewalt durchzusetzen $^{245}$. Die Wahl des neuen Stadtrates erfolgte nun ohne größere Zwischenfälle. Der neue Schöffenmeister, Henri de Gournay, Sieur de Talange schwor feierlich den vollen Treueid auf den König ${ }^{246}$.Von einer Selbstständigkeit des Magistrates und einer nur lockeren Protektion des Königs war also nun keine Rede mehr.

Trotzdem kam es bereits kurz nach Arbeitsbeginn der neuen und königstreuen Stadtverwaltung zum Konflikt mit dem Bailliage-Gericht: Als der Schöffenmeister und seine conseillers (wie der Rat nun statt der alten Bezeichnung "Dreizehn « genannt wurde) für sich die Polizeiaufsicht beanspruchten, die in den meisten Städten Frankreichs Sache der Magistrate war, wurden sie von den Richtern am königlichen Bailliage-Gericht auf die Kehrseite der zu Beginn als so schmeichelhaft empfundenen Gleichstellung mit Paris aufmerksam gemacht: Dort waren den städtischen Amtsträgern alle Polizeibefug-

${ }^{242}$ Vgl. dazu das Journal des Jean Bauchez. Charles ABEL, Ernest de BOUTEILLER (Hg.), Le journal de Jean Bauchez, greffier de Plappeville au dix-septième siècle (1551-1651), Metz 1868, S. 411: qui en [durch die Bailliage-Gründung] fut bien fasché, ce fut M. de Lambert, grand Gouverneur pour Sa Majesté en la dicte ville, disant que cela ne se seroit jamais conclu du temps des aultres Gouverneurs, dont pour le pensant apaiser d'une prune verte il fut mis grand Bailly dudict Bailliage.

${ }^{243}$ Sinngemäße Übertragung der Autorin: ...dont homme ne scauroit presque estimer si cher qu'elles se vendoient, ibid. S. 412.

${ }^{24}$ Sinngemäße Übertragung der Autorin: tous bourgeois furent bien esbahys de voir tel reschangement de toutes choses, fut descriptures qu'ancien droit, tellement que plusieurs murmures, querelles et disputes en provindrent depuis entre les bourgeois, ibid.

${ }^{245}$ Arrêt des conseil du roi vom 6.4.1641, BnF, N.a.fr. 22670, fol. 4f.

${ }^{246}$...que vous garderez et ferez garder de tout votre pouvoir la fidélité et obéissance due au Roi, votre souverain seigneur... Zitiert nach ZELLER, Réunion, Bd. 2, S. 296. 
nisse entzogen und lagen bei den königlichen Repräsentanten am Châtelet ${ }^{247}$. Noch unter der Federfuhrung der Kommissare Jerôme Cauchon und Jacques Doumengin war nur wenige Tage nach der Wahl des neuen Magistrates eine Ordonnanz der bailliage erlassen worden, die dem neuen Magistrat ausdrücklich untersagte, Richterfunktionen - auch in kleineren Polizeisachen - wahrzunehmen, und die Eide der Zunftmeister zu empfangen ${ }^{248}$. Die Stände der Stadt wandten sich trotz des ausdrücklichen Verbotes des Parlaments an den conseil du roi ${ }^{249}$, während ihre Gegenseite bereits ein ausführliches Traktat mit dem Titel Pour monstrer que les maire \& echevins de l'hostel de ville ou maison commune de la ville de Metz sont mal fondez en l'instance qu'ils ont intentée au conseil privé du Roy drucken und verbreiten ließen ${ }^{250}$.

Bemerkenswert ist hierbei, daß sich die Metzer Stände in ihrem Gesuch an den königlichen Rat offenbar nicht mehr auf ihre angestammten franchises et libertés und das Reichsrecht, sondern auf die Rechte der principales villes du Royaume und die Ordonnanz von Moulins beriefen ${ }^{251}$. Hiermit wird offensichtlich ein neuer Bezugsrahmen für die rechtliche Argumentation geschaffen, in dem die Stände ihre Stadt Metz nun trotz aller Kritik an der Einzelregelung nicht mehr als Reichsstadt, sondern als französische Stadt begriffen. Mit einem Rundbrief an vier Minister, einem umfangreichen cahier des doléances und einer persönlichen Deputation nach Paris erinnerte das praktische Vorgehen der Stadt allerdings weiterhin an frühere Proteste ${ }^{252}$.

Mit arrêt vom 19. Dezember 1641 wurde dem Anliegen der Stadt Metz teilweise stattgegeben und dem dortigen Magistrat die Verwaltung der städtischen Finanzen und allgemeinen Polizeiaufgaben zugesprochen. Alle Richterfunktionen - auch in Polizeisachen - verblieben allerdings beim königlichen Bailliage-Gericht, ebenso wie die Befugnis, entsprechende Regelungen und Ordonnanzen zu erlassen ${ }^{253}$. Im Jahr 1644 wurde die Frage nach der Polizeibefugnis in Metz noch einmal aufgeworfen, nach Angaben des Magistrates vor allem wegen der zahlreichen Mißstände, die sich seit der Errichtung der bailliage eingebürgert hatten. Doch die Entscheidung war endgültig, und von den alten Rechten des Magistrates blieb nur die Ehre, bei Prozessionen und öffent-

\footnotetext{
${ }^{247}$ Vgl. dazu PETRY, »Les grands mangent les petits«, S. 179-196.

${ }^{248}$ Ordonnanz vom 21.6.1641, EMMERY, Recueil, Bd. 1, S. $453 \mathrm{f}$.

249 Arrêt vom 26.7.1641, BnF, N.a.fr. 22670, fol. 25f., EMMERY, Recueil, Bd. 4, S. 172 (Anm.).

${ }^{250} \mathrm{BnF}$, N.a.fr. 22670 , fol. 17 f.

${ }^{251}$ Vgl. referierten Text in arrêt des conseil du roi vom 9.8.1641, BnF, N.a.fr. 22670, fol. 32 und EMMERY, Bd. 1, S. 453-456.

${ }^{252}$ Vgl. dazu BnF, N.a.fr. 22670, fol. 38-40 (Schreiben der conseillers an den Minister, 12.9.1641), 41-44 und 64-68 (cahier des doléances, o.D.) sowie fol. 46f. (Brief der Metzer Gesandten in Paris, 19.10.1641).

${ }^{253}$ Ibid. fol. 49-55 (arrêt vom 19.12.1641).
} 
lichen Zeremonien direkt hinter dem Gouverneur zu schreiten, auf gleicher Höhe mit den Beamten der bailliage ${ }^{254}$.

Weniger erfolgreich war die Errichtung der königlichen bailliage in Vic-surSeille als Hauptort des Hochstiftes Metz abgelaufen. Auch hier hatte man, allerdings erst im September 1641, einen Kommissar vor Ort geschickt, der das bischöfliche Gericht auflösen und die königlichen Richter einsetzen sollte. Die Wahl war auf Louis Gillot, lieutenant am siège royal in Toul, gefallen, ein Mann, der bisher nicht gerade durch seine konziliante Natur aufgefallen war $^{255}$. Louis Gillot war aber auch mit den Verhältnissen in Vic sehr gut vertraut: Schon 1634 war er im Auftrag des Parlaments von Metz dort gewesen und hatte dort die Archive der bischöflichen Verwaltung durchgesehen ${ }^{256}$.

Nachdem Louis Gillot die Aufhebung des bischöflichen Bailliage-Gerichtes verkündet hatte, beschlossen der Bischof, seine Vasallen und die Amtsträger, gemeinsam den conseil du roi anzurufen und um die Bewahrung des Gerichtes zu bitten. Der Metzer Bischof, der bereits dem Parlament nur unter Konzessionen zugestimmt hatte, argumentierte ähnlich wie in früheren Denkschriften mit dem souveränen Charakter seines Hochstiftes, der Reichszugehörigkeit, und den großen finanziellen Einbußen sowie dem Autoritätsverlust, den ihm die Aufhebung seines Bailliage-Gerichts beschere. Er war auf Gillot nicht gut zu sprechen und kritisierte, daß ausgerechnet ein Mann wie dieser, der überall durch sein »Ausscheren« bekannt sei, vom Parlament mit der Errichtung eines neuen Gerichtes beauftragt worden war. Die Beteiligung der Protestanten am Parlament schürte zudem die Befürchtung, daß die neuen Ämter von ceux de la religion pretendue de Metz et autre telles gens eingenommen würden. Daneben erinnerte der Bischof erneut an Schulden von 300000 livres, die der König noch bei ihm habe ${ }^{257}$.

Die Amtsträger des Bischofs schlossen sich der Remonstration an und betonten, daß sie während der kriegerischen Auseinandersetzungen stets auf der Seite des Königs gestanden hätten und nun einen besseren Dank für ihre Treue erwarteten $^{258}$. Die heftigen Proteste des Bischofs und seiner Amtsträger waren tatsächlich erfolgreich: Mit Urteil vom 31. Dezember 1642 hob der conseil du roi die königliche bailliage in Vic-sur-Seille wieder auf ${ }^{259}$. Wie schlecht die

\footnotetext{
${ }^{254}$ ZELLER, Réunion, Bd. 2, S. $298 \mathrm{f}$.

${ }^{255}$ Bei Betrachtung der Quellenbestände war Gillot sicherlich der königliche Amtsträger in den Trois-Évêchés, uber den die meisten Beschwerden geführt wurden. Vgl. nur AMAE, CP Lorr. 8, fol. 117 (1627); CP Lorr. 14, fol. 392; Institut, Godefroy 273, fol. 71, 85, 95, 97 und 171.

${ }^{256}$ MICHEL, Biographie, S. 198.

${ }^{257} \mathrm{BnF}$, fr. 16890 , fol. 207-210, weitere Exemplare: Institut, Godefroy 338, fol. 152 und AMAE, CP Lorr. 31, fol. 504.

${ }^{258} \mathrm{BnF}$, fr. 16890 , fol. $209 \mathrm{v}$.

${ }^{239}$ Ibid. fol. 390-393.
} 
Stimmung unter den alten Amtsträgern in Vic war, erfuhr der Kommissar Gillot vom Offizial des Bischofs, der ihm berichtete, im Haus des Schöffen Jacquemin hänge ein Stammbaum des Königshauses, der unter anderem den Kardinal Richelieu beleidige. Beim anschließenden Verhör vor dem Parlament stellte sich heraus, daß die Amtsträger der bischöflichen bailliage bei einem Essen im Hause Jacquemins ihrer Wut freien Lauf gelassen hatten und den dort aufgehängten Stammbaum unter Anspielung auf die 1631 von Duchesne konstruierte Abstammung Richelieus von Ludwig VI. (le Gros), den Kardinal und seine , Vorfahren ( mit wenig schmeichelhaften Beinamen wie »le Grosgros « ergänzten ${ }^{260}$.

Auch in Toul regte sich Protest gegen die geplante königliche bailliage: Das Domkapitel sah seine Rechte - und, da das Bistum zu diesem Zeitpunkt noch immer vakant war, auch die des Bischofs - bedroht und sandte eine ausführliche Remonstration an den König, in der ähnliche Argumente vorgebracht werden wie im Schreiben des Bischofs von Metz: Die Bischöfe von Toul seien Princes de l'Empire und hätten als diese ebenso wie das Domkapitel das Recht, alle Regalien, auch das der Gerichtsbarkeit, auszuüben. Auch hier wurde der König an die Garantien erinnert, die er anläßlich der Errichtung des Parlaments gegeben hatte (Bewahrung der Privilegien etc.). Daneben wurden auch finanzielle Argumente vorgebracht: Stadt und Umland seien viel zu arm, um noch eine weitere Institution neben dem Parlament zu finanzieren ${ }^{261}$.

Während man sich in Toul der Entscheidung für die bailliages beugen mußte, konnte der Magistrat von Verdun, der ebenfalls gegen die Neuordnung protestiert hatte, gewisse Zugeständnisse erreichen. Schon im März wurde allen Stadträten zugestanden, im Amt zu bleiben. Erst nach dem Tod der jeweiligen Amtsträger sollte dann nach dem neuen Verfahren gewählt werden ${ }^{262}$.

\section{Resümee}

Betrachtet man die Ereignisse in den Jahren nach 1633 scheint es - nicht nur wegen der in der vorliegenden Arbeit gewählten Perspektive der Rechtspolitik, daß diese Ereignisse in großem Maße von dem Parlament bestimmt wurden. Mit dieser Institution haben sich die Kräfteverhältnisse nachhaltig verschoben. Ein Grund dafür war, daß sich die Anzahl der nicht zum Militär gehörenden

${ }^{260}$ A.D. Moselle B 2125.

${ }^{261}$ AMAE, CP Lorr. 32, fol. 457.

${ }^{262}$ LE MOIGNE in: GIRARDOT (Hg.), Histoire de Verdun, S. 146, KIEFFER, Verdun, S. 32. 
Amtsträger des Königs in Metz von einem président und einem procureur du roi sowie möglicherweise einem Schreiber und einem Stellvertreter des procureurs (wie dies für Toul und Verdun überliefert ist) enorm erhöhte. Der Parlamentspräsident Bretagne zählte zwei Jahre nach der Parlamentserrichtung bei einer Gesamtbevölkerung von knapp 20000 Menschen ganze 510 Personen, die direkt beim Parlament beschäftigt waren oder von diesem abhingen $^{263}$. Damit hatte das Gericht zahlenmäßig sogar das Militär überholt, denn als auswärtige Mitglieder der Garnison vor Ort zählte Bretagne lediglich 300 Personen ${ }^{264}$. Wenn man dann bedenkt, daß die Angehörigen des Parlaments zum Großteil nicht aus der Region stammten, wie dies sonst üblich war, ist damit eine deutliche Veränderung des städtischen Sozialgefüges in Metz zu vermuten.

Diese soziale Bedeutung des Parlaments eröffnet auch eine neue Perspektive auf den Widerstand, der diesem Gericht vor allem von den Magistraten in Metz entgegengesetzt wurde. Möglicherweise vermag dies auch zu erklären, warum sich die wesentlich geringeren Proteste gegen das Parlament in Toul und Verdun dort in dem Moment verstärkten, in dem eine Verlegung des Gerichts in diese Städte angestrebt wurde.

Die Tatsache, daß man in Metz kaum einheimische Richter einsetzte, war wohl vor allem darin begrundet, daß hier nicht wie bei den Parlamentsgründungen in den neugewonnenen Gebieten Frankreichs gegen Ende des 15. und Anfang des 16. Jahrhunderts auf eine bestehende Institution zurückgegriffen wurde $^{265}$. Das Parlament von Metz als Neugründung quasi aus dem Nichts weist insofern bereits auf die Parlamentsgründungen des Hochabsolutismus unter Ludwig XIV. und Ludwig XV. ${ }^{266}$ und ist die erste dieser Art in Frankreich.

Betrachtet man die Eröffnungsfeierlichkeiten, wird das Bemühen um die Außenwirkung des Parlaments deutlich. Das Parlament setzte sich hier sowohl physisch als auch symbolisch eindrucksvoll in Szene. Die ausgeklügelten Sitzordnungen in der Kathedrale und während der Eröffnungssitzung des Gerichts beispielsweise setzten das Gericht in Beziehung zu den anderen Kräften in der Stadt und machten auch optisch Rangfolgen und Solidaritäten sichtbar. Adressat der Eröffnungsfeierlichkeiten in Metz war hierbei nicht nur die lokale Elite aus Magistraten, Kirchenmännern und Juristen, sondern auch die breite Bevölkerung, die sich auf dem Platz vor Gericht und Kathedrale versammelt

${ }^{263}$ AMAE, CP Lorr. 28, fol. 55f.

${ }^{264}$ Sowie weitere 120 Soldaten aus anderen Regimentern, die sich zu diesem Zeitpunkt kurzfristig in Metz aufhielten, ibid.

${ }^{265}$ Vgl. Jacques POUMAREDE, Jack THOMAS, Introduction, in: DIES. (Hg.), Les parlements de province, Toulouse 1996, S. 15.

${ }^{266}$ Ibid. S. 16. 
hatte, um das prächtige Spektakel zu erleben. Der »Mercure Français« informierte auch Leser außerhalb der Trois-Évêchés ausführlich von den Ereignissen. Richelieus Bemuhen um ,Öffentlichkeitsarbeit` spiegelt sich auch in diesem Einzelereignis wider ${ }^{267}$.

Wie die breite Masse der Bevölkerung zum Parlament von Metz stand, ist aus den vorliegenden Quellen kaum herauszulesen. Berichte dartiber, daß diese sich ein Parlament regelrecht herbeigesehnt habe, stammten stets von königlichen Amtsträgern oder den französischen Interessen nahestehenden Personen. Die Entscheidungen der Ständeversammlungen, von denen jedoch nicht bekannt ist, in welchem Maße sie von den lokalen Eliten kontrolliert wurden, scheinen hingegen ein anderes Bild nahezulegen. Auch aus diesem Grund sollen deshalb in Kapitel sieben die tatsächliche Gerichtsnutzung und mögliche Verfahren wegen Majestätsbeleidigung und verwandter Delikte an dem Gericht untersucht werden.

Die Verkündigungszeremonien des Gründungsediktes bei den bischöflichen Bailliage-Gerichten liefen hingegen weniger festlich ab und zielten eindeutig auf die nun untergeordneten Richter. Hier bekamen die Parlamentsmitglieder teilweise deutliche Ablehnung zu spüren, die darin begründet war, daß es durch die Rekrutierung des Parlamentspersonals nicht gelungen war, die bischöflichen und städtischen Richter, deren Kompetenzen durch das Parlament beschränkt oder sogar ganz abgeschafft werden sollten, einzubinden. Gleichzeitig hatte die Errichtung des Parlaments als ubergeordnete Instanz zwar die Kompetenzen der bischöflichen und städtischen Gerichte beschränkt, an ihrem Bestand oder ihrer Bedeutung als erste Anlaufstelle bei Rechtsfragen jedoch nichts geändert. Der offene Widerstand, den die alten Eliten Initiativen wie dem Bemühen um Vereinfachung des Instanzenzuges oder den ersten Plänen zur Errichtung königlicher bailliages entgegensetzten, hat die Parlamentsarbeit deutlich erschwert.

Die Probleme des Parlaments von Metz wurden noch dadurch verstärkt, daß sich der dortige Gouverneur in seiner Ablehnung des Gerichts den alten Eliten vor Ort angeschlossen hatte. Hier wird ebenso wie in den Jahren zuvor am Beispiel des président und später auch am Beispiel des Intendanten deutlich, daß gerade bei Personen, die seit langer Zeit in den Trois-Évêchés eine Funktion im Dienst des Königs auslibten, immer die Gefahr bestand, daß diese sich die Interessen der Region zu eigen machten statt die der Zentrale ${ }^{268}$.

${ }^{267} \mathrm{Zu}$ Richelieus Propaganda، vgl. MOUSNIER, L'homme rouge, S. 443-484, sowie Gilles FEYEL, Richelieu et la Gazette. Aux origines de la presse et la propagande, in: Roland MOUSNIER (Hg.), Richelieu et la Culture, Paris 1987, S. 102-123.

268 Ähnlich POUMAREDE, ThOMAS, Introduction, in: DiES. (Hg.) Parlements de province, S. 19-21. 
Der Konflikt des Parlaments mit dem Gouverneur hatte jedoch noch eine andere Wurzel, nämlich den Kontrollanspruch über die Militärjustiz und damit uber bedeutende Fragen der Armeedisziplin, den das Parlament anmeldete. Die Parlamentserrichtung sollte auch verhindern, daß die Familie der Épernon/La Valette bei erneuten Konflikten mit der Krone wieder über ein beinahe unabhängiges Rückzugsgebiet verfügte. Doch als aufgrund der militärischen Situation selbst Richelieu den Rückzug des Parlaments aus Metz befürwortete, hatte er mit der Verlegung nach Toul auch ein Zurückweichen des Gerichts vor dem Gouverneur unterstützt.

Der Widerstand, den das Gericht dieser Verlegung nach Toul über anderthalb Jahre entgegensetzte, zeigt zudem, wie schnell die königlichen Amtsträger schon durch den Eigentumscharakter ihrer Ämter in offene Opposition zum König gelangen konnten. Die Angst um den materiellen Wertverlust durch geringere Attraktivität der Parlamentsämter für Kaufinteressenten verband sich hierbei, vor allem in der von Rigault aufgesetzten Protestschrift, mit einem Pflichtbewußtsein gegenüber dem Staatswohl, das notfalls auch über die direkte Anordnung des Königs gestellt wurde. In gewisser Weise weist dieses Verhalten und die Argumentation der Parlamentsangehörigen schon auf typische Konfliktlinien in der Fronde, deren Ereignisse in Metz im übrigen kaum Wellen schlugen ${ }^{269}$.

Im Sinne eines Kräftefeldes, innerhalb dessen sich die Rechtspolitik entspannt, zeigt sich hier zum einen, daß die Interessen der Zentrale und die der Amtsträger vor Ort erheblich differieren konnten. Diese für die Verwaltung des Ancien Régime typische Erscheinung führte jedoch zum anderen dazu, $\mathrm{da} B$ die einzelnen Akteure sich zwischen den Polen »Bevölkerung « und »Amtsträger« nicht immer einordnen lassen und sich mit ihren Interessen teilweise auch der anderen Gruppe anschließen. Um diese Bewegungen besser verstehen zu können, sollen deshalb im folgenden die Amtsträger in typischen Karrierewegen und das Verhältnis zwischen Bevölkerung und Parlament genauer untersucht werden.

${ }^{269}$ Zur Fronde allgemein siehe: Ernest KossMANN, La Fronde, Leiden 1954; Alanson Lloyd MoOTE, The Revolt of the judges. The Parlement of Paris and the Fronde 1643-1652, Princeton 1971; Michel PERNOT, La Fronde, Paris 1994. Die neueren Ergebnisse werden zusammengefaBt in: Roger DuCHENE, Pierre RONZEAUD ( $\mathrm{Hg}$.), La Fronde en questions. Actes du colloque de CMR 17 (Marseille 1988), Aix-en-Provence 1989. 
